\title{
Mutant screen for reproduction unveils depression-associated Piccolo's control over reproductive behavior
}

Gerardo A. Medrano ${ }^{1 \&}$, Manvendra Singh ${ }^{11,12, \&}$, Erik J. Plautz ${ }^{6}$, Levi B. Good ${ }^{6}$, Karen M. Chapman ${ }^{1}$, Jaideep Chaudhary ${ }^{1}$, Priscilla Jaichander ${ }^{1}$, Heather M. Powell ${ }^{1}$, Ashutosh Pudasaini ${ }^{2}$, John M. Shelton ${ }^{3}$, James A. Richardson ${ }^{4,5}$, Xian-Jin Xie ${ }^{7}$, Zoltán Ivics ${ }^{9}$, Christine Braun ${ }^{10}$, Frauke Ackermann ${ }^{10}$, Craig C. Garner ${ }^{10}$, Zsuzsanna Izsvák ${ }^{11, *}$ and F. Kent Hamra ${ }^{1,2,8,}$

Department of ${ }^{1}$ Pharmacology, ${ }^{2}$ Obstetrics \& Gynecology, Internal Medicine - Division of ${ }^{3}$ Cardiology, ${ }^{4}$ Pathology, ${ }^{5}$ Molecular Biology, ${ }^{6}$ Neurology and Neurotherapeutics, ${ }^{7}$ Simmons Comprehensive Cancer Center, ${ }^{8}$ Cecil H \& Ida Green Center for Reproductive Biology Sciences, University of Texas Southwestern Medical Center in Dallas, USA; ${ }^{9}$ Paul-Ehrlich-Institute, Division of Medical Biotechnology, Langen, Germany, German Center for Neurodegenerative Diseases (DZNE), ${ }^{10}$ Charité Medical University, Charitéplatz, Berlin, Germany, ${ }^{11}$ Max Delbrück Center for Molecular Medicine in the Helmholtz Society, Berlin, Germany, ${ }^{12}$ Department of Molecular Biology \& Genetics, 526 Campus Road, Cornell University, Ithaca, NY 14853

\& Equal contributions

*Correspondence:

F. Kent Hamra kent.hamra@utsouthwestern.edu (Sperm stem cell lines/Rat models) and Zsuzsanna Izsvák www.mdc-berlin.de/izsvak (Transposon Mutagenesis) 


\begin{abstract}
Successful sexual reproduction involves complex, genetically encoded interplay between animal physiology and behavior. The rat provides a highly fecund mammalian model for studying how the brain impacts reproduction. Here, we report a forward genetics screen in rats to identify genes that affect reproduction. A panel of 18 distinct rat strains harboring Sleeping Beauty gene trap mutations were analyzed for the ability to reproduce. As expected, our mutant screen identified genes where reproductive failure was connected to gametogenesis (Btrc, Pan3, Spaca6, Ube2k) and embryogenesis (Alk3, Exoc6b, Slc1a3, Tmx4, Zmynd8). In addition, we identified Atg13 (longevity) and Pclo (neuronal disorders), previously not associated with an inability to conceive. Neurologically, Pclo is known to regulate the size of presynaptic vesicle pools. Here, dominant traits in Pclo mutant rats caused epileptiform activity and affected genes supporting GABAergic synaptic transmission (Gabra6, Gabrg3). Recessive traits in Pclo mutant rats transmitted altered reproductive behavior, as homozygous Pclo mutant rats produced gametes but neither sex would mate with wildtype rats. Pclo mutant rat behavior was linked to endophenotypes signifying compromised brain-gonad crosstalk via disturbed GnRH signaling and allelic markers for major depressive disorder in humans (Grm5, Htr2a, Sorcs3, Negr1, Drd2). Thus, by rat genetics, we identified Pclo as a candidate presynaptic factor required for reproduction.
\end{abstract}




\section{Author Summary}

Piccolo gene mutations have previously been identified in human cohorts diagnosed with behavioral syndromes that impact one's emotions, including depression and bipolar disorder. Although studies in human populations implicate changes to Piccolo's DNA sequence to enhanced susceptibility for behavioral disorders, studies in mouse models have yet to link Piccolo mutations to altered behavior. Here, by a novel genetics approach, we report Piccolo mutationdependent effects on reproductive behavior in rats, a finding that may turn out to be relevant to the behavioral effects that are associated with human Piccolo gene mutations. Thus, research aimed at understanding how Piccolo functions to regulate reproduction in rats could prove pivotal in our ability to understand neurological mechanisms that influence human emotions. 


\section{Introduction}

While a failure to reproduce sexually is often connected to physiological or developmental problems of the gonad, gamete or embryo, it is also commonly accepted that problems with sexual reproduction can be linked to physical fitness [1] or behavioral abnormalities [2]. Indeed, inborn social behaviors related to sex, defense and maternal care are elicited by sensory input that is processed by the central nervous system to promote successful reproduction [3].

Rats are highly fecund mammals and display robust appetitive and consummatory reproductive behavior $[4,5]$. In rats, sensory input to the limbic system that drives reproduction is mediated in large part via the olfactory system [olfactory epithelia > olfactory nuclei > main and/or accessory olfactory bulb > medial amygdala $>$ bed nucleus of stria terminalis $>$ medial pre-optic hypothalamic nucleus and ventromedial hypothalamus] [3]. Pheromones that signal mating bind to chemosensory olfactory receptors in the olfactory epithelium to elicit pre-copulatory social behaviors such as partner investigation, grooming and courtship [3, 6, 7]. Pre-copulatory sensory signals further culminate in copulatory and post-copulatory behavior that enable fertilization $[3,6$, 7]. Notably, the rat's olfactory epithelium is uniquely endowed with $\sim 1,400$ genes encoding olfactory receptors [8] and has long provided an experimental system to study mechanisms by which sensory input stimulates social behavior responses that affect reproduction $[3,6,7]$.

From the hundreds of genes essential for neuroendocrine/gonadal control over gametogenesis and fertilization [9], neurotransmission genes that govern sensory neuron-stimulated social behavior mediate the primary signals that initiate reproduction $[3,6,7]$. Social responses such as pleasure, attraction, fear, aggression and avoidance that affect reproduction are processed by the limbic system to modulate motivational responses $[2,10]$. Innate reproductive behaviors are driven by afferent sensory neurons that innervate the limbic system in mammals and are driven by sex and sex hormones (estrogen and testosterone) [6, 7]. Abnormalities in the cortico-limbic networks that integrate survival-driven reproductive behavior with emotional awareness and memory play crucial roles in the etiology of human "affective disorders", including depression, bipolar disorder, autism, anxiety and addiction, and represent neurological health conditions [11-13]. 
In this study, we aimed to identify novel genes required for reproduction. Our intention was to reach out from the circle of obvious candidates and uncover novel layers of reproductive biology, remaining as open as possible to finding the unexpected. Therefore, instead of taking a targeted approach, we chose an unbiased, forward mutagenesis strategy to identify new genes that impact reproduction using the rat model.

Sleeping Beauty transposon genomic insertions occur randomly, with 35\% frequency of landing in a gene transcribed by RNA polymerase II [14-16]. Gene trapping by random, Sleeping Beautymediated insertion of a selectable marker (e.g. $\beta$-geo) into RNA Polymerase II transcription units provides a powerful technology for introducing disruptive mutations into genes on a genome-wide scale. The ability to select for recombinant spermatogonial stem cell libraries harboring Sleeping Beauty transposon gene trap (gt) insertions has enabled large-scale production of novel mutant rat strains for analyses in forward genetic assays [17].

In the current study, a panel of Sleeping Beauty mutant rat strains derived from a spermatogonial gene trap library were tested for impaired reproduction phenotypes. In addition to genes required for gamete and embryo development, our mutant screen unveiled new genetic connections between reproduction, fitness and social behavior. Among the reproduction genes, we identified Atg13, which has generally been connected to longevity in species ranging from yeast to plants and humans. We also identified phenotypes in Pclo-deficient $\left(P c l o^{\text {gt/gt }}\right)$ rats that hold potential to model humans diagnosed with neurological disorders [18-20]. 


\section{Results}

\section{A set of mutations affects reproduction}

To identify genes essential for reproduction, we conducted a forward genetic screen using rats derived from a spermatogonial library of Sleeping Beauty insertional mutations [17] (Fig 1). Each mutant rat strain tested inherited a copy of Sleeping Beauty inserted within a distinct protein coding gene ( $n=17$ gene trap insertions + 1 untrapped gene insertion) (S1 Fig and S1 Table). In total, 12 of 18 mutant genes analyzed proved to be essential for reproduction (Fig 2A and S2 Table). Inability to reproduce was linked to a variety of phenotypes that included gametogenesis defects

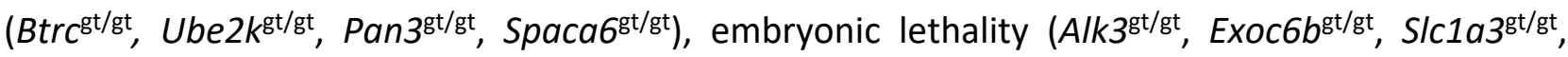
$\left.T m \times 4^{\mathrm{gt} / \mathrm{gt}}, Z m y n d 8^{\mathrm{gt} / \mathrm{gt}}\right)$, end-stage organ failure $\left(A \operatorname{tg} 13^{\mathrm{gt} / \mathrm{gt}}\right)$ and impaired behavior $\left(P c / 0^{\mathrm{gt} / \mathrm{gt}}\right.$, $\left.D \lg 1^{\mathrm{wt} / \mathrm{gt}}\right)$ (S3 Table and S4 Table).

\section{Mutations that disrupt distinct steps in rat spermatogenesis}

Homozygous gene trap mutations in Btrc, Ube2k and Pan3 blocked spermatogenesis at premeiotic, meiotic and post-meiotic steps, respectively (Fig 2B, S2A and S2B). Only residual numbers of malformed spermatozoa were detected in $B t r c^{\mathrm{gt} / \mathrm{gt}}$ males, and no epididymal spermatozoa were observed in Ube2 $\mathrm{k}^{\mathrm{gt} / \mathrm{gt}}$ or Pan3 ${ }^{\mathrm{gt} / \mathrm{gt}}$ males (Fig $\mathbf{2 C}$ and S3 Table). In corresponding Ube $2 \mathrm{k}^{\mathrm{gt} / \mathrm{gt}}$, Btrc $\mathrm{gt}^{\mathrm{gt} / \mathrm{gt}}$ and Pan3 ${ }^{\text {gt/gt }}$ genotypes, spermatogenic arrest was reflected by reduced testis size (Fig 2D and S3 Table). Btrc, Ube2k and Pan3 provide a novel set of reproduction models, where the infertility is the result of developmental problems of the gonad.

\section{A group of mutant rats develop gametes, but do not reproduce}

Rats with homozygous mutations in the Spaca6, Atg13 and Pclo genes produced both eggs and sperm (Fig 2C, S2A and S2C). However, neither sex of $A t g 13^{\mathrm{gt} / \mathrm{gt}}$ and $\mathrm{Pclo} \mathrm{O}^{\mathrm{gt} / \mathrm{gt}}$ rats were able to reproduce, as was the case with Spaca6 ${ }^{\mathrm{gt} / \mathrm{gt}}$ males (Fig $2 \mathbf{A}$ and $\mathbf{S 2}$ Table). Spaca6 ${ }^{\mathrm{gt} / \mathrm{gt}}$ females produced relatively normal sized litters when paired with wt males (Fig 2A and S2 Table). Mating behavior appeared normal in Spaca6 ${ }^{\text {gt/gt }}$ males when compared to wt males as supported by the presence of spermatozoa in vaginal swabs ( $n=4$ breeder pairs). Spaca6 ${ }^{\mathrm{gt} / \mathrm{gt}}$ males had normal size testes (Fig 2D). While Spaca6 ${ }^{\text {gt/gt }}$ epididymides had slightly reduced numbers of spermatozoa (Fig 
2C), their moderate deviation in sperm counts could not explain the observed infertility phenotype. The reproductive failure of Spaca6 $6^{\text {gt/gt }}$ males might be more likely associated with the recently suggested role of this immunglobulin-like protein in regulating sperm-egg membrane fusion [21].

\section{Reproduction defects in Atg13 mutants correlate with reduced longevity.}

Whereas Autophagy related 13 (Atg13) is required for autophagic flux and reaching an optimal lifespan in plants and animals (S4 Table)[22-24], the role of Atg13 in additional reproductionrelated traits is unknown. The insertional mutation resulted in a truncated form of Atg13 predicted to lack exon 16 (Atg13 ${ }^{\mathrm{e} 16}$ ) (Fig 3A). Atg exon 16 encodes the 25 carboxyl-terminal amino acids in Atg13 (Fig 3A). Expression of $A \operatorname{tg} 13^{\Delta \mathrm{e} 16}$ generated a protein that resembled wt ATG13: it was abundant in testes, with lower levels in other tissues (Fig 3A inset). All male Atg13 ${ }^{\text {gt/gt }}$ mutants were characterized by reduced testis size and epididymal sperm counts compared to wt (Fig 2C, D) but had relatively high testis-to-body weight and epididymis-to-body weight ratios (S3 Table). Atg13 ${ }^{\text {gt/gt }}$ cauda epididymal spermatozoa flagella were immotile and displayed more detached heads and tails than WT ( $n=4 /$ genotype).

Beside the abnormal spermatozoa of males, all $A \operatorname{tg} 13^{\mathrm{gt} / \mathrm{gt}}$ rats inherited pathologies associated with premature death at 3-5 months of age (Fig 3B). The livers and kidneys of ${\text { Atg } 13^{\mathrm{gt}} \mathrm{gt}}^{\mathrm{gt}}$ rats were abnormal (Fig 3C), with the liver containing cells scattered throughout histological sections displaying small spherical vacuoles, consistent with an accumulation of triglycerides (Fig 3D). All the kidneys that were examined displayed marked glomerulonephritis and moderate tubule interstitial disease (Fig 3E). Homozygous Atg13 ${ }^{\text {gt/gt }}$ animals $(n=3)$ from one of three pedigrees also demonstrated edematous paws and digits in adult animals (Fig $\mathbf{3 F}$ ).

Consistent with Atg13's biological function, changes in the relative abundance of autophagy markers LC3a-I/II and p62 were found in Atg13 ${ }^{\mathrm{gt} / \mathrm{gt}}$ embryonic fibroblasts (Fig 3G). Rapamycin treatment synergized with $A \operatorname{tg} 13^{\mathrm{gt} / \mathrm{gt}}$ to increase LC3a-I/II and p62 relative abundance in fibroblasts, implicating Atg13's COOH-terminal peptide in regulating mTorc-dependent autophagy signals (Fig 3G). The reproduction defects in both female and male $A \operatorname{tg} 13^{\mathrm{gt} / \mathrm{gt}}$ rats correlated with adult-lethal 
pathologies, and in males, Atg13 ${ }^{\mathrm{gt} / \mathrm{gt}}$ was further complicated with abnormal spermatozoa. Thus, the cause of infertility of $A \operatorname{tg} 13^{\mathrm{gt} / \mathrm{gt}}$ rats is a cumulation of general fitness problems.

\section{Compromised neurotransmission in Pclo mutants}

Despite their reproductive failure (Fig 2A), Pclogt/gt mutant rats did not display any obvious dysfunction during gametogenesis (S2A and S2C Fig). Numbers of epididymal spermatozoa from Pclogt/gt rats were relatively normal (Fig 2C). However, spermatozoa from Pclogt/gt rats were not found in vaginal swabs of WT females (6 of 6 breeder pairs) (Fig 4A, and spermatozoa from WT males were not detected in Pclogt/gt females (6 of 6 breeder pairs) (Fig 4A), suggesting that the mating did not actually occur.

Pclogt/gt rats harbor the Sleeping Beauty gene trap in Pclo intron 3, deleting exons 4-25 (Pclo ${ }^{\mathrm{SB} \Delta 4-25}$ rats) (Fig 4B). Pclo encodes multiple protein isoforms (70-560kDa) that are primarily localized in the cytomatrix of pre-synaptic neurons and have been implicated to play a key role in synaptic transmission [25]. While Piccolo is expressed in various tissues, including testis, it is dominantly enriched in the brain, where it is relatively abundant in the cerebellum, pituitary gland, cortex, hypothalamus and nucleus accumbens (GTEX Portal_PCLO).

The unconsummated mating alongside with the dominant distribution of Pclo transcripts in the brain let us hypothesize that the reproductive failure in $P c / o^{\text {gt/gt }}$ rats was associated by neurological abnormalities. Thus, to gain insights into Piccolo's role in reproductive phenotypes, we used samples from both testes and brain tissues of $P c l o^{\mathrm{gt} / \mathrm{gt}}, P c l o^{\mathrm{gt} / \mathrm{wt}}$ and $P c l o^{\mathrm{wt} / \mathrm{wt}}$ animals ( 6 mo old), and subjected them to RNA sequencing (RNA-seq). As expected, Pclo transcripts were readily detected in the brain (Fig 4C), whereas the testicular expression of Pclo was low (<0.1 FPKM) (S5 Table). In the brain, the gene trap insertion reduced Pclo transcript abundance by $>8.5$-fold in homozygous Pclogt/gt rats (Fig 4C), while no significant transcriptional changes of Pclo could be detected in heterozygous Pclowt/gt rats (Fig 4 C). Similarly, at the protein level, Pclo was reduced by $>95 \%$ in the brains of $P c / o^{\text {gt/gt }}$ rats, but Pclo was not significantly affected in $P c / o^{\text {wt/gt }}$ compared to Pclo ${ }^{\text {wt } / w t}$ littermates (Fig 4D). Thus, expression from a single Pclo allele appears to drive relatively 
normal levels of the gene product, and the phenotype that was observed appears to be connected to the allelic origin of Piccolo.

Our transcriptome analysis of $P c o^{\mathrm{gt} / \mathrm{gt}}$ and $P c l 0^{\mathrm{wt} / \mathrm{wt}}$ rats revealed a higher number of differentially expressed genes (DEGs) in the brain (754) than testis (88), while 16 genes were affected in both tissues (FPKM > 2 and log2 fold change $|1|$ and E-FDR < 0.01) (Fig 4E and S5 Table). Inclusive to the 16 DEGs that were affected in both brain and testes, Tspo, Ces1d, Folr1 and Adh1 (Fig 4E and S5 Table) regulate steroid hormone/vitamin biosynthesis, signaling and transport in the blood stream [26-29]. Despite similar Piccolo RNA/protein abundance in Pclo ${ }^{\mathrm{wt} / \mathrm{wt}}$ and $\mathrm{Pclo}{ }^{\mathrm{wt} / \mathrm{gt}}$ rat brains, 325 genes were differentially expressed $(\log 2 \mathrm{FC}|1|)$ in the brains of heterozygotes compared to wildtype or homozygotes (Fig 4F and S5 Table), reflecting robust allelic effects.

Gene Ontology (GO) analyses of DEGs revealed the most significantly down-regulated processes in Pclogt/gt vs Pclo ${ }^{\mathrm{wt} / \mathrm{wt}}$ rats included Synaptic Transmission and Neurogenesis gene sets $(\mathrm{p}<0.000006$; S6 Table), consistent with our hypothesis that lack of reproduction by Pclogt/gt rats was associated with a neurological defect. A prominent cluster of 80 downregulated Synaptic Transmission genes in the brain (Fig 5A) included the gamma-aminobutyric acid (GABA) signaling pathway (GO:0007214, p=0.0000009) (Fig 5B and S6 Table). The most significantly affected genes in both $P c l o^{g t / g t}$ and $P c l o^{\text {wt } / g t}$ rats were members of the GABA(A) receptor gene family, Gabra6 (GABA(A) Receptor Subunit Alpha 6) in the brain and Gabrg3 (GABA(A) Receptor Subunit Gamma-3) in the testis (Fig 4G). Notably, the expression of both, Gabra6 in brain, and Gabrg3 in testes, dropped to undetectable levels (FPKM $<0.01)$ in $P c l o^{\mathrm{wt} / \mathrm{gt}}$ and $P c / o^{\mathrm{gt} / \mathrm{wt}}$ rats, suggesting a dominant phenotype in Pclo ${ }^{\text {tt/gt }}$ mutants that results in a close-to KO phenotype for each $\mathrm{GABA}(\mathrm{A})$ receptor subunit in respective tissues (Fig 4G). While Gabra6 is dominantly expressed in the cerebellum of the brain (GTEX Portal_Gabra6, FPKM >1), Gabrg3 is expressed in various regions of the brain, primarily in the hypothalamus, in the pituitary gland and has a moderate enrichment in the testis (GTEX Portal Gabrg3, FPKM>1).

\section{Disturbed hormonal secretion in Pclo mutants}


In addition to downregulated Synaptic Transmission gene sets (Fig 5A), a prominent cluster of Hormonal Secretion gene sets was also downregulated in Pclogt/gt $r a t$ brains compared to Pclowt/wt animals (Fig 5B). Pathway analyses (PANTHER) further deciphered that the affected genes in Pclogt/gt fall most frequently into major signaling pathways of the Gonadotropin-releasing hormone (GnRH) receptor, followed by Wnt, Chemokine-cytokine and CCKR signaling (S3A Fig).

Importantly, GABA and GnRH signaling are functionally connected. During development the GABA signal, which depolarizes $\mathrm{GnRH}$ neurons, regulates overall GnRH neuron maturation (e.g. migration to the brain). Various $\mathrm{GABA}(\mathrm{A})$ receptor subunits are differentially expressed during the process of GnRH-1 maturation [30], and Gabra6 is a receptor subunit within embryonic GnRH-1 neurons that is replaced by Gabra2 during adult life [30]. Signaling pathways coupled to the GnRH receptor gene set control the hypothalamic-pituitary-gonadal axis that is critical for gamete development [31], and for regulating reproductive behavior [32, 33].

The reported Gabra6-positive GnRH neuronal progenitors led us to wonder whether the close-toKO Gabra6 phenotype in Pclogt/gt rats altered GnRH neuron migration patterns during development, and in turn, compromised establishment of proper GnRH receptor signaling. However, a direct assessment of GnRH neurons in the brains of adult Pclo ${ }^{g t / g t}$ rats revealed normal numbers of GnRH immuno-positive cells in the pre-optic area of the hypothalamus that projected normally into the medial eminence (Fig 5C, D and S3B Fig). Thus, GnRH neuron development within the pre-optic area of $P c / o^{g t / g t}$ rats did not appear to be affected by diminished Gabra6 expression, suggesting that other signaling mechanisms might, at least partially, compensate for Gabra6 function during the process of $\mathrm{GnRH}$ neuron maturation.

Nevertheless, excitatory GABA neurons activate GnRH neurons [34] throughout adult life to affect the rate of $\mathrm{GnRH}$ synthesis and the pattern of $\mathrm{GnRH}$ release [35] as mechanisms that regulate activity of the $\mathrm{GnRH}$ receptor. In this context, we identify Heterotrimeric G-proteins as a significantly affected category in Pclo mutants, through which the GnRH receptor predominantly transmits its signals (S3A Fig). Furthermore, a major fraction of the G-protein coupled receptors 
(GPCRs) involved in conducting GnRH signaling on gonadotrophs are differentially enriched in the brains of Pclo ${ }^{g t / g t}$ rats compared to $P c l o^{\text {wt } / g t}$ and $P c l o^{\text {wt } / \text { wt }}$ rats (S4A Fig). Similarly, the cascade involved in mobilizing $\mathrm{Ca}^{2+}$ from InsP3-sensitive intracellular pools, required for the secretion of gonadotropins, is impaired in Pclogt/gt rats (S4B Fig).

Downregulation of GnRH-dependent GPCR- and $\mathrm{Ca}^{2+}$-stimulated processes may well affect end products of the $\mathrm{GnRH}$ receptor signaling pathway (e.g. luteinizing hormone, LH; follicle-stimulating hormone, FSH; S3D Fig). Blunted expression of GnRH signaling gene sets corresponded to reduced plasma levels of LH and FSH in the Pclo KO compared to WT (S4C Fig) Furthermore, analyzing the transcript levels of potential target genes that might be regulated by $\mathrm{LH}, \mathrm{FSH}$ and/or testosterone [36] in Pclogt/gt vs Pclowt/wt rats revealed that about half of the dysregulated genes in Pclogt/gt testes responded to a particular hormonal stimulation in a reverse order (rho $=-0.31$ and $p$-value $<2.2 e-$ ${ }^{16)}$ (Fig 5E and S4D Fig). Gabrg3, Ces1d, Card9, Ins/3 and Hp appeared among the most affected targets of $\mathrm{LH}, \mathrm{FSH}$ and/or testosterone in Pclogt/gt mutant rat testes (Fig 5F). Thus, downregulated neuroendocrine GnRH signaling failed to normally activate several gonadotropin-responsive target genes in the testis, likely contributing to the Pclo-deficient rat's infertility phenotypes.

\section{Pclo deficiency up-regulates hypothalamic genes associated with social behavior}

In addition to GABA(A) signaling, we evaluated further altered gene signatures in the $P c / o^{\text {gt/gt }}$ rat brain encoding factors that would function upstream of GnRH signaling pathways (S3A-D Fig), potentially adding an additional layer to the complexity of the infertility phenotype. This approach identified a set of transcripts encoding neuroendocrine hormones that was selectively upregulated in Pclogt/gt rat brains by $>3$-fold vs wt (Fig 4F and S5 Table). Among the upregulated genes, Npy, Pmch, Hcrt1, Trh and Avp are known to physiologically regulate GnRH-1 neuron activity, energy balance and/or social behavior [37-40]. Collectively, the down-regulated GnRH receptor signaling, as well as the up-regulated hypothalamic polypeptide hormone signaling gene profiles in Pclodeficient rats would suggest that Piccolo embodies a candidate presynaptic factor that regulates reproductive behavior in response to an organism's physiological state. 


\section{Reproductive failure in Pclo mutant rats is associated with neurological and behavioral defects}

To follow up on altered synaptic transmission gene sets observed in the Pclo mutants as well as the potential behavioral aspects of the infertility phenotype, we conducted studies on brain function and behavior. Consistent with dominant $\operatorname{GABA}(\mathrm{A})$ endophenotypes (Fig 4G), both Pclowt/gt and $P c l o^{\mathrm{gt} / \mathrm{gt}}$ mutations increased mean seizure frequencies ( $\geq 8$-fold) compared to $P c / o^{\mathrm{wt} / \mathrm{wt}}$ littermates ( $\mathrm{n}=8 /$ genotype) (Fig 6A, left). The EEG morphology in Pclowt/gt and $\mathrm{Pclo}{ }^{\mathrm{gt} / \mathrm{gt}}$ rats resembled short duration absence-type seizures, displaying a characteristic 6-8 Hz spike-wave generalized onset (Fig $6 \mathrm{~A}$, right), with no convulsive activity, and functionally verifying the significance of altered Synaptic Transmission gene sets (Fig 5A, B).

To find out if the Pclo mutation is associated with a behavioral phenotype, we monitored precopulatory social interactions that normally occur between female and male rats, including courtship, grooming and genital investigation. We observed that, in contrast to their Pclowt/wt littermates ( $\mathbf{S 1}$ Video), female and male $P c / o^{\text {gt/gt }}$ rats exhibited a relative disinterest in courting the opposite sex upon being introduced into the same cage with $P c l o^{\mathrm{wt}} / \mathrm{wt}$ rats $(\mathrm{p}=0.0002$ compared to WT littermates, $\mathrm{n}=8$ /genotype) (S2 and S3 Video). Our monitoring indicated that instinctive, normal pre-copulatory social interactions were suppressed in both female and male $P c l o^{\text {gt/gt }}$ rats (S2 and S3 Video).

In contrast to the compatible precopulatory behavior shared between $P c / o^{\mathrm{wt} / \mathrm{wt}}$ and/or $P c / o^{\mathrm{gt} / \mathrm{wt}}$ rats (S1, S4 and S5 Video), the social phenotype displayed by Pclogt/gt rats of both sexes included overt aggression, biting, lunging and posturing (Fig 6B and S2, S3, S6 Video). Thus, in addition to the hormonal imbalance, Pclo-dependent neural connections function to regulate conspecific sensory responses that are likely to contribute to the infertility phenotype of $P c l o^{\mathrm{gt} / \mathrm{gt}}$ rats. Moreover, by $\sim 3$ months of age, the aggressive phenotypes displayed by Pclo mutants selectively rendered the male Pclogt/gt rats so severely socially incompatible (S6 Video) that they could not be housed with male or female littermates any longer, independent of littermate genotype ( $n=14$ of 14 male Pclogt/gt rats). 


\section{Recessive Pclo traits are mappable to allelic markers for major depressive disorder}

Mapping to a recessive phenotype, the Synaptic Transmission category included a severely compromised Glutamatergic Excitation gene set (GO:0051966, p=0.00000001) in the brain of Pclogt/gt rats (e.g. DEGs in the Pclogt/gt, but not in Pclo ${ }^{g t / w t}$ mutants) (S6 Table). Pclo clustered with Grm5, Htr2a, Negr1, Drd2, Cacna2D1 and Dlg1 [41] as transcripts selectively down-regulated in Pclogt/gt rats (Cluster 1, Fig 7A). Among the most significantly downregulated genes were Grm5 (Glutamate Metabotropic Receptor 5) and Htr2a (the serotonin [5-Hydroxytryptamine] Receptor 2A) (S5 Table). Both Grm5 and Htr2a function as GPCRs in the signaling cascade that controls calcium mobilization and PKC activation [41, 42]. Alongside glutamatergic neurotransmission, dopaminergic neurotransmission (e.g. Drd2) and Calcium signaling (e.g. Cacna2D1 and Dlg1) also contributed to the recessive phenotype in Pclo mutants (S6 Table).

Intriguingly, 6 dysregulated genes in the recessive Pclo traits (e.g. Pclo, Grm5, Cacna2D1, Negr1, Sorcs3 and Drd2) are among the recently reported 44 key risk factors of major depressive disorder (MDD), identified by a human genome-wide association study containing 135,458 MDD cases and 334,901 controls [43] (Fig 7B). To test for a potential association between the biological processes dysregulated in $P c l o^{g t / g t}$ rats and a neurological disorder, we data-mined and compared the transcriptome of brain samples derived from an MDD rat model [44] and our Pclogt/gt rat (Fig 7C). Our strategy identified a robust list of 408 genes that were similarly affected in both models ( $r$ ho $=$ 0.306 and $p$-value $=2.916 e-08)$ (Fig 7D), supporting a transcriptome-level relationship between the biological processes dysregulated in Pclogt/gt rats and a rat model of MDD. Notably, the shared list of MDD transcripts encoded genes that have been associated with various features of depression, such as cortical dementia (e.g. Trim47), moodiness (e.g. S100A9), enhanced microglial activation (e.g. Tspo) and depression followed by immune challenge (e.g. Fig 7D). Notably, Gabra6, among the most highly dysregulated genes in Pclo KO rats, was also not detectable in the hypothalamus and cortex samples of the MDD rat model (Fig 7E), connecting Gabra6 with both Pclo and MDD phenotypes $[20,45]$.

\section{Cross-species analysis reveals robust differences in rat reproduction mutant phenotypes}


Finally, we compared our rat phenotypes to data recorded in other species harboring loss-offunction mutations in orthologous genes (S4 Table). Nine mutated rat genes (Atg13, BtrC, Dlg1, Grik3, Pclo, Slc1a3, Spaca6, Zmynd8, and Ube2k) have mutated orthologs in mice [Mouse Genome Informatics (MGI), the International Mouse Phenotype Consortium (IMPC) and the National Center for Biological Information (NCBI) databases], whereas 5 of our mutated orthologs have been characterized in plants, yeast, worms, flies or frogs (Alk3, Atg13, Btrc, Dlg1, Pan3) (S4 Table). Strikingly, the 'shortened life span' caused by mutations in Atg13 has been reported across multiple species including plants, yeast, worms, flies, mice and rats (S4 Table).

In humans, genome-wide association studies (GWAS) have implicated orthologs for 12 of the mutant rat genes we analyzed (Abca13, Alk3, Atg13, Btrc, Dlg1, Exoc6b, Fstl5, Gsgl1, Grik3, Pclo, Slc1a3, Ube2q2) as either risk factors or candidate risk factors for various human disease processes (S4 Table). About half of these reported disease factors are associated with neurological/behavioral disorders (e. g. Abca13, Dlg1, Exoc6b, Grik3, Pclo, Slc1a3) (S4 Table).

Of note, $D / g 1^{g t / w t}$ rats displayed reduced fecundity and altered behavior (S4 Table). Intriguingly, a Dlg1-null mutation was reported to disrupt courtship and mating in flies [46]. Dlg $1^{\text {tt/wt }}$ rats were consistently observed in back cage corners, remained socially isolated following pairing with respective wildtype males, and only produced offspring on one occasion ( $n=4$ pups; 3 wildtype males and 1 mutant female) after pairing for extended periods ( $>10$ months) with different wildtype males and appeared otherwise healthy (See S4 Table). In Pclogt/gt rat brains, Dlg1 (a.k.a. Synapse-Associated Protein 97 or SAP97) was observed as the most downregulated gene in in the GO category of Calcium Signaling (S4B Fig), unveiling a potential connection between Pclo and Dlg1 to regulate conspecific social behavior.

Our comparative analysis provided several additional examples where gene mutations analyzed here in rats produced significantly different phenotypes in another species with orthologous gene mutations (S4 Table). Such differences may reflect the quality of the knockout and/or speciesdependent differences in biology. As a prime example, while fertility and behavior is normal in Pclo- 
bioRxiv preprint doi: https://doi.org/10 1101/405985; this version posted March 19,2020. The copyright holder for this preprint (which was not certified by peer review) is the author/funder, who has granted bioRxiv a license to display the preprint in perpetuity. It is made available under aCC-BY-NC-ND 4.0 International license.

deficient mice [47], our Pclo mutants were infertile, complicated with social incompatibility, and a potential genetic link with depression (Figs 4A, 7B-E and S2, S3, S6 Videos). 


\section{Discussion}

Here, we characterize a pool of 12 distinct mutant rat strains that are unable to reproduce (Alk3, Atg13, Dlg1, Btrc, Exoc6b, Pan3, Pclo, Slc1a3, Spaca6, Tmx4, Ube2k, Zmynd8). The mutant rat strain pool was derived from a library of recombinant spermatogonial stem cells harboring randomly inserted Sleeping Beauty gene trap transposons [17]. The reproduction phenotypes we identified in rats were all associated with different steps in spermatogenesis or embryonic lethality except for three mutant strains (Atg13, Dlg1, Pclo). Of the later mutants, Atg13 and Pclo strains stood out by exhibiting a "complex" phenotype that allowed us to decipher novel aspects of reproduction.

Our Atg13 ${ }^{\text {gt/gt }}$ rats displayed abnormal autophagy markers, gross renal abnormalities and inflammation-like phenotypes that preceded death in early adulthood. Atg13 (Autophagy related 13) is the master metabolic sensor for toggling between AMPK1-dependent cellular torpor (i.e. autophagy) and ULK1-repressed mTORC1-dependent cell growth. The Atg13 ${ }^{\text {gt/gt }}$ rat phenotype might be related to the loss of a phylogenetically conserved Ulk1-binding peptide encoded by Atg13's terminal exon (Fig 3A). Atg13's $\mathrm{COOH}$-terminus has been implicated in activating the main autophagy-initiating complex [48]. Similar to the rat $A \operatorname{tg} 13^{\text {gt/gt }}$ phenotype, dysfunctions in $\operatorname{Atg} 13$ have been associated with nephrological/immunological problems and autophagy in humans [49, 50]. Mice harboring either a frameshift mutation in Atg13 exon 5 or a gene trap in Atg13 exon 1, by contrast, exhibit a more severe phenotype and die in utero due to heart defects [51]. Notably, the end-stage pathology of $A \operatorname{tg} 13^{\mathrm{gt} / \mathrm{gt}}$ rats correlated with immotile, degenerating caudal epididymal spermatozoa, likely associated with the premature aging phenotype. While the Atg13 ${ }^{\mathrm{gt} / \mathrm{gt}}$ rat represents an excellent model to study the connection between premature aging, fitness and fertility, our Pclo and Dlg1 mutants highlighted how traits linked to human neurological disorders might disrupt rat reproductive behavior.

Curiously, the Pclo ${ }^{\mathrm{SB} \Delta 4-25}$ mutation disrupted reproduction, but induced more "global" changes in the brain transcriptome than in the testis, suggesting a possible crosstalk between the brain and gonads. The most significant changes in both tissues affected GABAergic signaling via GABA(A) receptors. Our data support a scenario, where the infertility phenotype is connected to the altered 
composition of $\mathrm{GABA}(\mathrm{A})$ receptor subunits associated with the $\mathrm{GnRH}$ signaling cascade. GABA has been shown to play an important role in the maturation of gonadotrophin-releasing hormone (GnRH)-1 neurons during development and in regulating the pulsatile release of GnRH in adults [30, 34, 35]. Accordingly, impaired GnRH receptor signaling would translate into reduced responsiveness of testicular target genes (Fig $\mathbf{5 E - G ) . ~ T h e ~ m o s t ~ s i g n i f i c a n t l y ~ d y s r e g u l a t e d ~ t a r g e t ~}$ gene in Pclo ${ }^{g t / g t}$ rat testes also encodes a GABA(A) receptor, Gabrg3, gamma subunit 3 (Fig 4G), suggesting that a crosstalk between brain and testes may also involve a mechanism that regulates Gabrg3-dependent GABAergic tone. Thus, our Pclo ${ }^{\mathrm{SB} \triangle 4-25}$ mutant rat model holds potential to help address the long-standing debates on how GABAergic tone in the brain and testes is functionally linked to GnRH neuron receptor activity [52] and reproductive behavior [32, 33].

The Pclo ${ }^{\mathrm{SB} \Delta 4-25}$ rat model exhibited additional GABAergic neuropathies. Both homozygous and heterozygous $P$ clo ${ }^{\mathrm{SB} \Delta 4-25}$ rats develop generalized seizures (Fig 6A), similar to seizures observed in children homozygous for Pclo $0^{\Delta 6-s t o p}$ of pontocerebellar hypoplasia type $3 a$ [18]. Disturbed GABAergic synaptic transmission in Pclo mutants likely affects the balance between inhibition and excitation and thereby provokes seizures, manifesting itself as epileptiform activity [34, 35]. Pontocerebellar hypoplasia type $3 a$ has been also connected with impaired recycling of synaptic vesicles regulated by Pclo $[53,54]$.

Intriguingly, among the differentially expressed genes in $P c / 0^{\mathrm{SB} \Delta 4-25}$ rats, we found an association with the transcriptomes in brains of rats modeling depressive disorders (Fig 7B-E). The top candidates of depression-related genes identified here as DEGs in Pclo rats $^{\mathrm{SB} \Delta 4-25}$ were involved in glutamatergic and dopaminergic neurotransmission and neuronal calcium signaling pathways, and further matched key allelic neurological markers identified independently in large scale GWAS cohorts of humans diagnosed with MDD (e.g. Pclo, Grm5, Htr2a, Sorcs3, Negr1, Drd2) [43, 55]. Affective disorder and limbic system neurotransmission phenotypes reported in MDD patients harboring Pclo variants were previously demonstrated to disrupt emotional processing in response to conspecific facial cues $[56,57]$. By analogy, the pre-copulatory mating behavior and aggression 
phenotypes reported here in Pclo ${ }^{\mathrm{SB} \Delta 4-25}$ rats demonstrate Piccolo's potential control over sensory responses to social cues.

Importantly, while both Piccolo and Gabra6 variants are associated with MDD and altered emotional processing based on studies in humans $[20,45]$, no direct sexual connection to either gene has been reported in humans. The functional significance of the tight control of Gabra6 expression by Pclo has yet to be investigated, but one possibility is that a loss of synaptic integrity leads to Gabra6 down-regulation [58]. Even so, reports on Gabra6 KO mice suggest that they exhibit no behavioral phenotypes $[59,60]$, indicating that the complexity of phenotypes observed in Pclogt/gt rats may not be entirely explained by Gabra6-deficiency alone.

In contrast to neurological phenotypes caused by Pclo variants in rats reported here, mice that lack the full calcium sensing coil-coil domain encoded by Pclo exon 14 ( $\mathrm{ClO}^{\Delta 14} \mathrm{mice}$ ) behave normal and are fertile $[47,61]$. While we did not observe a significant difference in homozygous $P c l o^{\mathrm{SB} \Delta 4-25}$ rat body weights (S3 Table), homozygous $P c l 0^{\Delta 14}$ mice displayed reduced body weights and enhanced postnatal mortality, consistent with a negative energy balance [47]. In contrast, $P$ clo ${ }^{\mathrm{SB} \Delta 4-25}$ rats, curiously, like Dlg1-deficient flies [46], exhibit reproduction abnormalities that may be attributed to suppressed pre-copulatory and copulatory behavior. When compared to Pclo-dependent sensory responses in humans [56, 57], Pclo-dependent reproductive behavior displayed by Pclo ${ }^{\mathrm{SB} \Delta 4-}$ ${ }^{25}$ rats might point to compromised synaptic transmission in the olfactory system, limbic system and/or hypothalamus as brain regions impacted by Pclo deficiency.

In summary, by forward genetics in rats, we annotated $P c l o$ as a candidate reproductive factor that controls behavioral responses to sensory input. Studies can now be aimed at defining how Pclodependent neural circuits in the rat control social behavior, and prospectively, how Pclo-dependent neuroendocrine signaling integrates social responses with metabolic state. 


\section{Materials and Methods}

\section{Mutant rat strains}

Mutant rat strains harboring Sleeping Beauty Beta-Geo gene trap transposons were originally transmitted to F1 progeny from a donor recombinant spermatogonial stem cell library [17]. Recipient males were bred with wildtype females to produce a panel of mutant rat strains that harbor gene traps within protein coding genes [17]. Eighteen heterozygous F1 mutant rat strains (S1 Fig, S1 Table) derived from an original pool of >150 Sleeping Beauty b-Geo gene trap strains (Cryopreserved at UT Southwestern's Mutant Rat Resources: SSCLBR Cat \& RRID) were maintained live due to an expressed interest in and/or requests for respective strains by researchers representing a broad spectrum of biomedical fields (S2 Table). Rat protocols were approved by an Institutional Animal Care and Use Committee (IACUC) at the University of Texas Southwestern Medical Center, as certified by the Association for Assessment and Accreditation of Laboratory Animal Care International (AAALAC).

\section{Rat breeding for forward screen}

A panel of 18 heterozygous F1 Sleeping Beauty gene trap mutant rat strains was evaluated for their ability to reproduce (S2 Table). Based on a $\sim 11 \mathrm{~kb}$ deletion from mouse Chr17 containing Spaca6 and Has1 that blocked sperm-egg fusion in mice [21], the Spaca6 ${ }^{\mathrm{gt} / \mathrm{gt}}$ mutant rats were included in the current study to provide a control gene trap hypothesized to disrupt reproduction. Additionally, Rgs22 ${ }^{\mathrm{gt} / \mathrm{gt}}$ mutant rats were included in the current study to provide a control gene trap hypothesized not to disrupt reproduction, due the gene trap cassette being inserted in the $3^{\prime}$ to $5^{\prime}$ orientation.

Founder-derived F1 mutant progeny were crossed with wildtype rats to produce F2 mutants. Males and females for 17 of 18 F2 heterozygous mutant strains successfully produced littles, of which, mean litter sizes produced by 15 of the $\mathrm{F} 2$ heterozygous mutant strains were comparable in size to wildtype Harlan, Sprague Dawley rat stocks (S2 Table). Only Dlg $1^{\text {wt } / g t}$ females were identified as sub-fertile after pairing heterozygotes with wildtype rats of opposite sex for $>10$ months. One $D \lg 1^{\mathrm{wt} / \mathrm{gt}}$ female produced a single mutant female in one total litter ( $\mathrm{n}=4$ pups); however, the 
second generation $D \lg 1^{\mathrm{wt} / \mathrm{gt}}$ female failed to reproduce litters after subsequent pairings with fertile males for 12 months.

Male and female (F3) heterozygous mutants from the other 17 strains were generated from separately outbred parents (Harlan, SD) and paired at 3-4 months of age to generate F4 homozygous mutants. Heterozygous mutant pairs that produced litters and displayed markedly reduced Mendelian rates towards generation of homozygous mutant progeny were classified as embryonic lethal (i.e. no homozygous mutant F4 progeny; $n>50$ total pups/strain except for Alk $3^{\mathrm{wt} / \mathrm{gt}}$ mutants, where $\mathrm{n}=35$ ). Viable $\mathrm{F} 4$ homozygous mutants were paired with proven wildtype breeders (Harlan, SD) of opposite sex between 3-4 months of age to identify recessive mutations that transmitted significant changes in mean litter size. If F4 homozygotes failed to generate progeny by 3-4 months after pairing with a wildtype breeder, they were paired with a second wildtype proven breeder from Harlan, SD. Genes were classified as required for rat reproductive success under our standard housing conditions if homozygous mutations blocked multiple F4 progeny ( $n=2-4$ homozygous mutant breeders/sex) from producing any offspring after pairing with 2 consecutive wildtype proven breeders of similar age over a span of $>10$ months. Adult lethal homozygous Atg13 mutants demonstrated health decline between 3-4 months of age (i.e. shortly after setting up breeder pairs).

\section{Genotyping mutant rat progeny}

Endogenous gene-specific PCR primers near Sleeping Beauty integration sites were used in combination with transposon-specific primers to genotype progeny from familial generations F1 and F2 for newly generated mutant rat lines. Genomic sites of transposon integration were defined in F1 progeny by splinkerette PCR[17] and sequence analysis alignment on genome build RGSC v3.4 (Rn4). Genotyping results were verified by Southern blot hybridization assays of genomic DNA digested with $\mathrm{Xmnl}$ and $\mathrm{Xbal}$ using a probe specific for the EGFP transgene and the LacZ portion of the $6-G e o$ insert in the Sleeping Beauty transposon[17]. Restriction analysis by Southern blot estimated $\sim 7$ transposon integrations/stem cell genome, which following random segregation and ploidy reduction during meiosis yielded $\sim 3.5$ transposon integrations/donor-derived spermatozoa, 
or founder-derived mutant F1 pup[17]. Phenotypes in Atg13, Btrc, Pclo, Pan3, Spaca6 and Ube2k Sleeping Beauty mutant rat strains were analyzed in F4 animals produced from F3 breeder pairs harboring only their respective, Sleeping Beauty transposon integration (i.e. single copy gene trap transposon F3 mutants).

\section{Phenotype database and literature analysis}

European Conditional Mouse Mutagenesis Programme (EUCOMM), Knockout Mouse Project (KOMP), Mouse Genome Informatics (MGI), International Mouse Phenotype Consortium (IMPC) and National Center for Biological Information (NCBI) databases provided records on mouse gene orthologs. NCBI PubMed, Gene and the Rat Genome Database (RGD) provided records on rat gene orthologs. Human phenotypes for mutant orthologs were searched in publicly available NCBI Genetics and Medicine databases, including: PubMed, Gene, Online Mendelian Inheritance in Man (OMIM), Database of Genotypes and Phenotypes (dbGaP); and the National Human Genome Research Institute's Catalog of Published Genome Wide Association Studies (NHGRI GWAS Catalog). NCBI PubMed and Gene were searched to identify phenotypes available for Arabidopsis, Saccharomyces, Caenorhabditis, Drosophila, Danio and Xenopus species. PhenomicDB database verified results from above database searches across all species. Literature comparisons for phenotypes caused by mutations in rat and mouse orthologs published independent of the current study are summarized in S4 Table. Embryonic lethality or postnatal lethality prior to reproductive age was categorized as blocking reproduction. Fishers Exact t-test (two-tailed) was used to analyze phenotypic proportions of viable versus sub-viable, viable versus embryonic lethal, fertile versus infertile, mating versus non-mating.

\section{Sperm counts and copulation}

Epididymides were harvested from adult rats between 120-180 days of age and dissected free of surrounding fat and connective tissue for measuring weights, counting spermatozoa and histological analysis. To estimate spermatozoa numbers/rat, each epididymal caput and cauda were dissected apart from the corpus and separately placed into $3.8 \mathrm{~cm}^{2}$ wells of a 12 well plate containing 1.5 ml DHF12 nutrient media [Dulbecco's Modified Eagles Medium:Ham's F12 (1:1); 
Sigma, D8437] 1x antibiotic antimycotic solution (Invitrogen, cat. no. 15240-062). Spermatozoa were released by thoroughly mincing each epididymal piece for $30 \mathrm{sec}$ and allowing the spermatozoa to disperse into the medium for $25 \mathrm{~min}$. Large pieces of epididymal tissue were removed with forceps and discarded. One $\mathrm{ml}$ of the epididymal cell-containing medium was carefully filtered through a $100 \mu \mathrm{m}$ cell strainer (BD Biosciences, Inc.) into a $1.5 \mathrm{ml}$ microfuge tube prior to counting using a Hemocytometer chamber. To assess breeding behavior and detect copulation, rats were paired with a single wildtype mate just prior to the end of the daily light cycle (4:00-5:00 pm central standard time). The following morning (7:00-8:00 am central standard time), each female was examined for the presence of spermatozoa in the vagina. A foam swab tip was used to collect a vaginal smear, which was then analyzed by phase contrast microscopy to detect presence of sperm.

\section{Analysis of RNA-seq data from Pclo rats}

Single end 100 bp RNA-seq libraries were prepared from brain, liver and testis tissues of 6-monthold Pclogt/gt $, \mathrm{Pclo}^{\mathrm{gt} / \mathrm{wt}}, \mathrm{Pclo}{ }^{\mathrm{wt} / \mathrm{wt}}$ rats. The libraries were run on Illumina Hiseq 2000 sequencer (Total number of reads was $\sim 550-600$ million). For basecalling we used the Illumina Casava1.7 software. Reads were than aligned to the reference human genome version rn6 by using Tophat2/bowtie2. This approach has provided a refseq_rn6 gene model that guided the assembly process of the transcriptome. We checked the quality of the sequencing and the mapping by Fastqc and by $R N A S e q Q C$, repectively. Due to the negligible technical variances, the read counts of a gene had a Poisson distribution, thus we could apply the single-replicate model to analyze the data. We calculated Read counts using featureCounts from the subread package (http://subread.sourceforge.net/). Fragments Per Kiolobase of RNA per Million mapped reads (FPKM) was calculated using bamutils (http://ngsutils.org/modules/bamutils/count/).

\section{Analysis of differentially expressed genes}

Random Variable1 $($ Var1 $)=$ n.l.x, where $x($ Random Variable2) is the expression level of a gene (e.g., in RPKM (Reads Per Kilo bases per Million reads) $n$ is reflecting the sequencing depth and $/$ is the gene length. The method proposed by Anders and Huber was used to calculate $n[62]$. To generate 
more robust and accurate Fold change values from unreplicated RNA-seq data, we determined the normalization constant and variance by pasting the two random variables in the published algorithm of:

(http://bioinformatics.oxfordjournals.org/content/early/2012/08/23/bioinformatics.bts515.full.p $\underline{d f+h t m l})$. To identify the Gene Ontology (GO) categories that were overrepresented in the Piccolo mutants, we compared samples from the brain and testis of $P c / o^{\mathrm{gt} / \mathrm{gt}}$ and $P c / o^{\mathrm{wt} / \mathrm{gt}} \mathrm{vs} P c l o^{\mathrm{wt} / \mathrm{wt}}$ rats, with the entire set of rat genes as a background.

\section{Electroencephalogram (EEG) recording and analysis}

Twelve adult rats ( 6 males, 6 females) were surgically prepared for EEG experiments with 4 rats in each experimental group $\left(P c l o^{\mathrm{wt} / \mathrm{wt}}, P \mathrm{Plo} \mathrm{o}^{\mathrm{wt} / \mathrm{gt}}, P \mathrm{Pll} \mathrm{g}^{\mathrm{gt} / \mathrm{gt}}\right)$. Rats were anesthetized using a gas anesthesia machine with $~ 3 \%$ isoflurane in a $1 \mathrm{~L} / \mathrm{min}$ mixture of $70 \%$ nitrous oxide and $30 \%$ oxygen. Four epidural recording electrodes made from \#00-90 x 1/8 inch stainless steel screws were placed at the following stereotaxic coordinates: A-P $\pm 2.0 \mathrm{~mm}$, lateral $\pm 3.0 \mathrm{~mm}$ and A-P $-4.0 \mathrm{~mm}$, lateral $\pm 3.0 \mathrm{~mm}$ along with a reference and ground screw over the olfactory bulb and cerebellum, respectively. Electrodes were attached by a flexible wire (kynar, 30 ga) to a custom 6-pin microconnector (Omnetics) and secured with dental acrylic. Rats received the analgesic buprenorphine $(0.05 \mathrm{mg} / \mathrm{kg})$ as necessary following surgery and were allowed to recover for at least 7 days prior to any experimentation. Following recovery from electrode implantation, each rat was placed in a custom acrylic recording cage (Marsh Designs, Peoria, AZ) and connected to a Tucker-Davis Technologies (Alachua, FL) RZ2/PZ3 neurophysiology workstation through a flexible cable suspended from the top of the cage with an interposed commutator to allow rats free access to food and water without twisting the cable. Continuous video/EEG (300 Hz sampling) was recorded for each rat simultaneously for 7 days and read by a user blinded to the experimental grouping for the presence of seizures and epileptiform activity. Seizure activity was marked at the beginning and end of each event to account for seizure duration, and the numbers of seizures per hour were calculated. 


\section{Western blot analysis}

To analyze Piccolo expression, brains were dissected from wildtype, heterozygous mutant, and homozygous mutant Sprague Dawley rats and homogenized in $1.5 \mathrm{ml} / 0.5 \mathrm{~g}$ tissue, ice-cold lysis buffer (50 mM HEPES, pH 8.0, 150 mM NaCl, 1 mM EDTA, 10\% glycerol, 1\% Triton X-100, 10 mg/ml aprotinin, $10 \mu \mathrm{g} / \mathrm{ml}$ leupeptin and 1 protease inhibitor Data Sett/12.5 ml) for 30s using a PTA-7 probe, setting 5, PT10-35 polytron (Kinematica). The homogenates were incubated on ice for 15$20 \mathrm{~min}$ and then centrifuged at $3000 \mathrm{xg}$ for $10 \mathrm{~min}$ at $4^{\circ} \mathrm{C}$ in a GPR Data Settop centrifuge (Beckman, Inc.). The supernatant solutions were centrifuged at $15,800 \mathrm{xg}$ for $15 \mathrm{~min}$ at $4^{\circ} \mathrm{C}$ in a microcentrifuge (Model 5042, Eppendorf, Inc.) and the resultant supernatant fractions were stored at $-80^{\circ} \mathrm{C} .160$ $\mu \mathrm{g}$ of protein was separated on 4-15\% Mini-Protean TGX gels (BioRad, Inc.), and then transferred to nitrocellulose. Samples were not heated prior to loading. Nonspecific, protein binding sites were blocked by incubating membranes overnight at $4^{\circ} \mathrm{C}$ in blocking buffer: TBST (Tris-buffered saline with Tween-20: $10 \mathrm{mM}$ Tris- $\mathrm{HCl}, \mathrm{pH}$ 7.5, $150 \mathrm{mM} \mathrm{NaCl}, 0.1 \%$ Tween-20) containing 5\% nonfat dry milk. Membranes were washed three times in TBST and incubated for $1 \mathrm{~h}$ at $22-24^{\circ} \mathrm{C}$ using rabbit anti-Piccolo (Synaptic Systems cat. no. 142002) diluted 1:2000 in blocking buffer. Membranes were washed three times in TBST $\left(0.3 \%\right.$ Tween-20) and incubated $45 \mathrm{~min}, 22-24^{\circ} \mathrm{C}$ with peroxidaseconjugated, anti-rabbit IgG (Jackson Immunoresearch) diluted 1:50,000 in blocking buffer. Membranes were washed three times in TBST and protein bands detected using the enhanced chemiluminescence detection method (ECL, Amersham, Inc.). Blots were stripped and re-probed with 1:20,000 dilution of mouse anti-TUBA1a (MU-121-UC, Biogenex, Inc.).

Rat embryonic fibroblast (REF) cultures were extracted in RIPA buffer (50 mM Tris pH 7.4, $150 \mathrm{mM}$ sodium chloride, $1 \mathrm{mM}$ EDTA, 1\% IPEGAL, 0.25\% deoxycholic acid) plus protease inhibitor and phosphatase inhibitor Data Setts (Roche Applied Science). $11 \mu \mathrm{g}$ protein was separated on NuPAGE 4-12\% Bis-Tris gels (Invitrogen, Inc.) and then transferred to nitrocellulose membranes. Nonspecific protein binding sites were blocked by incubating membranes overnight at $4^{\circ} \mathrm{C}$ in blocking buffer: TBS (Tris-buffered saline: $10 \mathrm{mM}$ Tris- $\mathrm{HCl}, \mathrm{pH} 7.4,150 \mathrm{mM} \mathrm{NaCl}$ ) containing 1X Western Blocking Reagent (Roche Applied Science, Inc.). Antibodies were diluted in TBS containing 0.5X Western Blocking Reagent $+0.1 \%$ Tween-20. Membranes were incubated in primary antibody 
for 1-2 hours at $22-24^{\circ} \mathrm{C}$. Membranes were washed 4 x 5 min in TBST (0.1\%-0.3\% Tween-20), incubated in IRDye secondary antibody for 45-60 min, washed again 4 × $5 \mathrm{~min}$, and scanned on an Odyssey Classic Quantitative Fluorescence Imaging System, Model 9120, Licor Biosciences, Inc. Images were analyzed with Odyssey software version 3.0.21. Primary antibodies: Rabbit anti-LC3A from Cell Signaling Technology, Inc, \#4599, 1:300; Mouse anti-Atg13 from Medical and Biological Laboratories, Ltd, \#M183-3, 1:1000; Guinea pig Anti-p62 from Medical and Biological Laboratories, Ltd, \#PM066., 1:2000. Secondary antibodies were all from Licor Biosciences: Goat anti-rabbit IRDye 800CW \#926-32211, 1:15000; Goat anti-mouse IRdye 680LT 1:20000; Donkey anti-guinea pig IRDye 800CW \#926-32411, 1:15000.

\section{ELISA on Rat Plasma}

Plasma LH and FSH levels were measured using ELISA Kits from CUSABIO according to the manufacturer's instructions (Rat FSH Cat\# CSB-E06869R; Rat LH Cat\# CSB-E12654r from CUSABIO).

\section{Histological sectioning and staining}

Hematoxylin/Eosin (H\&E), periodic acid-Schiff's (PAS) and Trichrome staining on histological sections from rat tissues were conducted by standard procedures at the Molecular Pathology Core Laboratory, UT Southwestern Medical Center in Dallas.

\section{Preparing frozen sections}

To prepare frozen testis sections for labeling with antibodies, testes were dissected from rats, perforated by puncturing three equally spaced holes in the tunica albuginea along each longitudinal axis of the testis using a 27 gauge needle, and fixed for $\sim 18 \mathrm{hr}$ at $4^{\circ} \mathrm{C}$ in $0.1 \mathrm{M}$ sodium phosphate buffer, $\mathrm{pH} 7.2$, containing $4 \%$ paraformaldehyde. Fixed testes were equilibrated through a $10 \%, 18 \%$ and $25 \%$ sucrose [wt/v, dissolved in $1 \mathrm{x}$ phosphate buffered saline (PBS; Invitrogen Inc, cat no. $14040-182)$ ] gradient by sequential overnight incubations $(\sim 24 \mathrm{hr})$ at $4^{\circ} \mathrm{C}$ in $20 \mathrm{ml}$ of each respective sucrose solution. Once equilibrated to $25 \%$ sucrose, testes were embedded in tissue freezing medium (Electron Microscopy Sciences Inc., \#72592) and frozen using a Shandon Lipshaw (\#45972) cryo-bath. Frozen testes were used to prepare a parallel series of 8 
$\mu \mathrm{m}$ cryo-sections. Frozen sections were stored at $-40^{\circ} \mathrm{C}$ until use in immunofluorescence assays as described below.

\section{Fluorescence immunohistochemistry}

Prior to labeling studies, sections were equilibrated in air to 22-24으 for $15 \mathrm{~min}$, hydrated in Dulbecco's phosphate-buffered saline (PBS) (Sigma, D8537) at 22-24으 for $10 \mathrm{~min}$, heat-treated at $80^{\circ} \mathrm{C}$ for 8 minutes in $10 \mathrm{mM}$ sodium citrate ( $\mathrm{pH} \mathrm{6.0)}$ and then incubated for $1 \mathrm{hr}$ at 22-24을 $\mathrm{C}$ blocking buffer [Roche Blocking Reagent $(1 \% \mathrm{v} / \mathrm{v})$ diluted in $0.1 \mathrm{M}$ Sodium phosphate buffer, containing Triton X100 (0.1\% v/v)]. Sections were then treated for $18-24 \mathrm{hr}$ at $22-24{ }^{\circ} \mathrm{C}$ with respective antibodies diluted in blocking buffer at the following concentrations: [1:400 mouse antiSall4 IgG (H00057167-M03, Abnova, Inc); 1:400 rabbit anti-phospho-H2A.X (Ser139) IgG (07-164, Millipore, Inc); 1:400 rabbit anti-phospho-Histone H3 (ser10) IgG (06-570, Millipore, Inc)] diluted into Roche blocking $(1 \% \mathrm{w} / \mathrm{v})$ reagent. After treatment with primary antibodies, sections were washed 3 times for $10 \mathrm{~min} /$ wash in $50 \mathrm{ml}$ PBS and then incubated for $40 \mathrm{~min}$ at 22-24으 with respective AlexaFluor594 (Invitrogen, Inc), or AlexaFluor488 (Invitrogen, Inc) secondary antibodies diluted to $4 \mu \mathrm{g} / \mathrm{ml}$ in PBS containing $5 \mu \mathrm{g} / \mathrm{ml}$ Hoechst 33342 dye (Molecular probes, cat no. H3570). After treatment with secondary antibodies, sections were washed 3 times at $10 \mathrm{~min} /$ wash in $50 \mathrm{ml}$ PBS. After the $3^{\text {rd }}$ wash in PBS, sections were cover-slipped for viewing using Fluorogel mounting medium (Electron Microscopy sciences, cat no. 17985-10). Images were acquired using an IX70 Olympus fluorescence microscope (Olympus Inc.) equipped with Simple-PCI imaging software (CImaging Systems, Compix, Cranberry Township, PA).

\section{Rat embryonic fibroblast culture}

Primary rat embryonic fibroblast (REF) cultures were prepared from E14.5 embryos dissected from wildtype female rats after mating with $A \operatorname{tg} 13^{\mathrm{wt} / \mathrm{gt}}$ male rats. Timed mating was established as described above in the section on Sperm Counts and Copulation. Uteri were dissected from pregnant females and washed with $10 \mathrm{ml}$ DHF12 medium, 1\% Penicillin-Streptomycin solution $(v / v)$. The heads and visceral tissue were removed from each isolated embryo. Visceral tissue was discarded. Tissue from the upper portion of the head was used to isolate genomic DNA and genotype embryos for the Atg13 gene trap mutation. The remaining thoracic portion was washed 


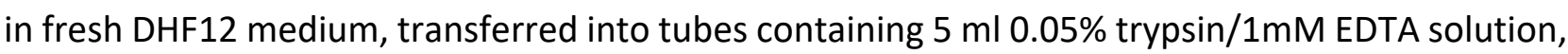
minced for 2 minutes and then incubated at $37^{\circ} \mathrm{C}$ for $20 \mathrm{~min}$. After incubation, REF culture medium [DMEM (Sigma, D5648-10XL), 10\% fetal bovine serum (Tissue Culture Biologicals, 104300), 1\% Penicillin/Streptomycin (Hyclone, SV30010)] was added to the cell suspension and the cells were dissociated further by gentle trituration (5 strokes) using a p1000 Eppendorf tip. The cell suspension was centrifuged $4 \mathrm{~min}$ at $120 \mathrm{xg}$ and the supernatant was discarded. The cellular pellet was retained, suspended to $15 \mathrm{ml}$ in fresh REF medium, plated into $10 \mathrm{~cm}$ plastic tissue culture dishes (Corning, Inc.) and then incubated at $37^{\circ} \mathrm{C}, 5 \% \mathrm{CO}_{2}$ overnight. REFs were fed $15 \mathrm{ml}$ fresh medium every $48 \mathrm{hrs}$, and sub-cultured using the 0.05\% trypsin/1mM EDTA solution to harvest attached cells from culture dishes every 2-3 days. Harvested REFs were passaged by plating at $10^{4}$ cells $/ \mathrm{cm}^{2}$ in $3 \mathrm{ml} / \mathrm{cm}^{2}$ REF medium. REF cultures were maintained at $37^{\circ} \mathrm{C}, 5 \% \mathrm{CO}_{2}$, and used for experiments at passage 4 . REFs were treated for $24 \mathrm{hr}$ with or without $3 \mathrm{mM}$ ammonium chloride (Fluka, 09718), 100 nM Rapamycin A (LC Laboratories, R-5000) and, or 3 nM Bafilomycin A1 (Sigma, B1793) prior to preparing lysates for western blots.

\section{Perfusion, Sectioning and Immunohistochemistry of rat brains}

Perfusion: Adult rats (P100) were first sedated in Isoflurane (Abbott GmbH \& Co. KG, Wiesbaden, Germany) and then deeply anesthetized with a mix of $20 \mathrm{mg} / \mathrm{ml}$ Xylavet (CO-pharma, Burgdorf, Germany), $100 \mathrm{mg} / \mathrm{ml}$ Ketamin (Inresa Arzneimittel GmbH, Freiburg, Germany) in 0.9\% $\mathrm{NaCl}$ (B/BRAUN, Melsungen, Germany). Afterwards the heart was made accessible by opening the thoracic cavity, and a needle inserted into the left ventricle and the atrium cut open with a small scissor. Animals were initially perfused with PBS and then with freshly made $4 \%$ PFA, before dissecting and further incubated for $24 \mathrm{~h}$ in $4 \%$ PFA at $4^{\circ} \mathrm{C}$. Brains were then cryoprotected in $15 \%$ and then $30 \%$ sucrose at $4^{\circ} \mathrm{C}$ for $24 \mathrm{~h}$. Brains were then frozen using 2-methylbutane (\#3927.1, CarlRoth, Karlsruhe, Germany) cooled with dry ice to $-50^{\circ} \mathrm{C}$ and stored at $-20^{\circ} \mathrm{C}$. Brain sectioning. 20 $\mu \mathrm{m}$ thin serial sections were cut from frozen brains using a cryostat (Leica Mikrosysteme Vertrieb $\mathrm{GmbH}$, Wetzlar, Germany). Slices transferred to a microscope slide (Superfrost Plus, \#H867.1, Gerhard Menzel B.V. \& Co. KG, Braunschweig, Germany), dried at RT for at least $1 \mathrm{~h}$ and stored at $20^{\circ} \mathrm{C}$. Immunohistochemistry. 3,3'-Diaminobenzidine (DAB) staining of $20 \mu \mathrm{m}$ coronal brain 
sections labeled with mouse anti GnRH antibody performed as previous described (Brinschwitz et al., 2010). In brief, thawed sections were dried for $30 \mathrm{~min}$ at RT and washed 3x for 10 min in PBS-T (PBS 1X (Thermo Fisher Scientific, Waltham, USA) + 0.025\% Triton X-100 (\#3051.2, Carl-Roth, Karlsruhe, Germany) and endogenous peroxidase was blocked for 10 min with $0.3 \% \mathrm{H} 2 \mathrm{O} 2$ in PBS, before blocking for $2 \mathrm{~h}$ at RT in blocking solution (PBS plus $10 \%$ normal goat serum and $1 \% \mathrm{BSA}$ ). Sections were then incubated in primary mouse anti GnRH antibody (1:500, HU4H, provided by $\mathrm{H}$. Urbanski, Oregon Regional Primary Center, Beaverton, OR) in blocking solution for $1 \mathrm{~h}$ at RT and 2 days at $4^{\circ} \mathrm{C}$. After washing sections were incubated in a secondary Biotin-conjugated antibody (goat anti mouse Biotin-SP, 1:1000, \#115-035-003, Dianova GmbH, Hamburg, Germany) in blocking solution for $1 \mathrm{~h}$ at $\mathrm{RT}$ and 2 days at $4^{\circ} \mathrm{C}$, before adding the $A B C$ reaction reagent (Vectastain $A B C$ Kit \#PK-6100, Vector Laboratories Inc., Burlingame, CA) for $1 \mathrm{~h}$ at RT and 1 day at $4^{\circ} \mathrm{C}$. After 1 day, sections were washed before adding the DAB solution (DAB peroxidase substrate Kit \#SK-4100, Vector Laboratories Inc., Burlingame, CA) for 1min. DAB reaction was stopped with purified water ( $\mathrm{ddH} 2 \mathrm{O})$ and sections were dehydrated in the following sequence: 2 min $70 \%$ ethanol (EtOH), 2 $\min 80$ \% EtOH, 2 min 95 \% EtOH, 2 min 99,9\% EtOH. Sections were cleared in Rotihistol (\#6640.4, Carl Roth $\mathrm{GmbH}$, Karlsruhe, Germany) until mounting in Entellan (\#1.07961.0100, Merck KGaA, Darmstadt, Germany).

Acknowledgements: Funding sources: This work was supported by National Institutes of Health grants to F.K.H. from The Eunice Kennedy Shriver National Institute of Child Health and Human Development: R01HD053889 and R01HD061575, The National Center for Research Resources: R24RR03232601; and The Office of the Director: R24OD011108. Neurological analyses on Pclo mutant rats were conducted by The Neuro-Models Facility (EJP, LBG) at UT Southwestern Medical Center, and supported by the Haggerty Center for Brain Injury and Repair. Z. Iv. was supported by grants from the Bundesministerium für Bildung und Forschung (NGFN-2, NGFNplus - ENGINE). Z. Iz. is supported by European Research Council, ERC Advanced [ERC-2011-AdG 294742]. CG is supported by the German Center for Neurodegenerative Diseases (DZNE) and DFG-SFB958. We thank Christine Römer and Ruth Ann Word for their critical comments.

Author Contributions: Designed research: MS, EJP, LBG, JMS, JAR, CCG, ZIz, FKH; Performed research: GAM, MS, EJP, LBG, KMC, JC, PJ, HMP, AP, JMS, CB, FA, FKH; Contributed unpublished 
bioRxiv preprint doi: https://doi.org/10 1101/405985; this version posted March 19,2020. The copyright holder for this preprint (which was not certified by peer review) is the author/funder, who has granted bioRxiv a license to display the preprint in perpetuity. It is made available under aCC-BY-NC-ND 4.0 International license.

reagents/analytic tools: ZIv, ZIz, FKH, Analyzed data GAM, MS, EJP, LBG, KMC, JMS, JAR, XX, ZIv, CB, FA, CCG, ZIz, FKH; Wrote the paper GAM, EJP, KMC, MS, JMS, JAR, ZIV, CCG, ZIz, FKH.

Competing interests: The authors declare no competing interests. 


\section{Figure Legends}

\section{Figure 1. Sperm Stem Cell Based Forward Screen for Rat Reproduction Genes}

Recombinant rat spermatogonial stem cell libraries are produced by Sleeping Beauty transposon genomic insertion. Spermatogonial libraries of randomly inserted Sleeping Beauty gene trap mutations are used to produce colonies of mutant rats. Novel Sleeping Beauty mutant rat strains are crossed to identify genes that impact reproduction. In the current study, eleven homozygous mutant rat strains generated were viable following birth ( 70\%), 6 were embryonic lethal ( 28\%) and 1 was scored as sub-viable postnatally ( $6 \%)(n=18$ mutant rat strains analyzed for ability to reproduce). Similar relative percentages were reported in mice by the European Conditional Mouse Mutagenesis Program (EUCOMM) and the Knockout Mouse Project (KOMP) [63].

\section{Figure 2. Gene Mutations that Cause Infertility in Rats}

(A) Mean litter size produced by crossing female and male homozygous Sleeping Beauty mutant rats (gt:gt) with wildtype breeders (WT). e = embryonic lethal; $d=$ dominant effect that disrupted F1 female mutant fecundity.

(B) Developmental steps during sperm maturation or fertilization disrupted by respective homozygous gene trap mutations (gt:gt) in rats. *Note: Btrc ${ }^{\text {gt/gt }}$ rats displayed pre-meiotic ( $\sim 5 \%$ tubules) and post-meiotic ( $15 \%$ tubules) spermatogenic arrest based on co-labeling with nuclear markers ( $\gamma \mathrm{H} 2 \mathrm{AX}$ and Hoechst 43332 dye).

(C) Mean testis weight (tan bars; left y-axis) and epididymal sperm counts (blue bars; right y-axis) from respective homozygous mutant rat strains ( $\pm S E M, n=4-6$ rats/strain). Measurements taken between postnatal days 120-180. Caudal epididymal spermatozoa from Spaca6 ${ }^{\text {gt/gt }}(n=6)$ and $P_{c}{ }^{\text {gt/gt }}(\mathrm{n}=4)$ rats displayed similar basal activity compared to wildtype.

(D) Testes from wildtype (Wt) and homozygous gene trap mutants (Mu). Scale bar, $5 \mathrm{~mm}$

Figure 3. Pathology linked to the $\mathrm{COOH}$-terminal 25 amino acids in rat Autophagy Related 13

(A) Diagram of Sleeping Beauty B-Geo gene trap in rat Atg13 intron 15 . The gene trap splices to

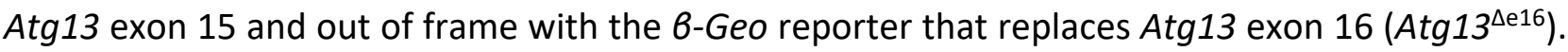
Atg13 exon 16 encodes the C-terminal 25aa of wildtype Atg13 and is predicted to be replaced by a 24aa epitope (blue font) derived from the gene trap construct, thereby, generating a similar size mutant protein. Inset: (top panel) western blot probing ATG13 in tissues from wildtype (WT) and homozygous mutant $A t g 13^{\text {gt:gt }}(\mathrm{Mu}$ ) rat littermates; (bottom panel) same blot probed for Gapdh. Arrowheads point to WT and Mu rat proteins with molecular size of ATG13 ( $65 \mathrm{kDa}$ ) and Gadph ( 37 kDa). Br, brain; SkM, skeletal muscle; Te, testis; Ht, heart; Ki, kidney; Lu, lung; Sp, spleen

(B) Kaplan-Meier estimator of postnatal survival for $\operatorname{Atg} 13^{\text {wt:wt }}$ (wildtype), ${\text { Atg } 13^{\text {wt:gt }}}^{\text {(heterozygous) }}$

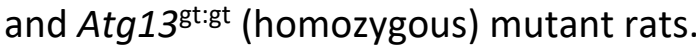

(C) Liver (top) and Kidney (bottom) from wildtype and homozygous mutant (Atg13 ${ }^{\text {gt:gt}) ~ l i t t e r m a t e s . ~}$ Liver scale bar, $2 \mathrm{~cm}$; Kidney scale bar $5 \mathrm{~mm}$.

(D) Hematoxylin and Eosin stained liver sections in Atg13 ${ }^{\text {wt:wt }}$ and Atg13 ${ }^{\text {gt:gt }}$ rats. Note, fatty liver in $A t g 13^{\text {gt:gt }}$ rats (arrows). Liver sections from littermates, postnatal day 110 . Scale bar $50 \mu \mathrm{m}$.

(E) Trichrome stained sections illustrating dramatic sclerosis of the glomerular tuft and fibrosis in Bowman's capsule of an Atg13 ${ }^{\text {gt:gt }}$ rat. Note proliferating epithelial cells lining Bowman's capsule 
(arrows). An adjacent tubule is dilated and filled with protein rich filtrate (asterisks). Kidney sections from wildtype and Atg13 ${ }^{\text {gt:gt }}$ littermates, postnatal D110. Scale bar $100 \mu \mathrm{m}$.

(F) Forearms of $A$ tg13 ${ }^{\text {gt:gt }}$ phenotype in one strain. Note swelling of left arm/digits. Scale, $5 \mathrm{~mm}$.

(G) Relative expression of the autophagy marker proteins Atg13, LC3a I, LC3a II and p62 compared to TUBA1a (loading control) in embryonic fibroblasts derived from wildtype and mutant rats following treatment with or without combinations of rapamycin, ammonium chloride $\left(\mathrm{NH}_{4} \mathrm{CL}\right)$ and bafilomycin-A1 (BAF-A)

\section{Figure 4. RNA profiling in mutant Piccolo rats}

(A) Pclo ${ }^{\text {wt:wt }}, P c l o^{\text {wt:gt }}$ and Pclogt:gt rat mating after pairing with wildtype breeders based on identification of spermatozoa in vaginal swabs. $(n)=8$ to 12 total breeder pairs/genotype, or 4 to 6 breeder pairs/sex/genotype for Pclowt:gt and Pclogt:gt mutant strains.

(B) Diagram of Sleeping Beauty B-Geo gene trap in rat Pclo intron 3. The gene trap splices to Pclo exon 3 , out of frame with the 6 -Geo reporter. The gene trap is predicted to replace the C-terminal 3805aa or 4010aa encoded by exons 4-25 of respective wildtype Pclo isoforms with a 24aa construct-derived epitope (blue font) to generate $P c l o^{\Delta \mathrm{e} 4-25}$.

(C) Relative abundance (FPKM values) of Pclo transcript isoforms in Pclowt:wt, Pclowt:gt and Pclogt:gt rat brains. 'NM_020098, encodes the full length 4880-amino acid isoform; ${ }^{\ddagger}$ NM_001110797, encodes the full length 5041-amino acid isoform.

(D) Western blot of Piccolo isoforms and TUBA1a in total brain lysates prepared from Pclowt:wt, Pclowt:gt and Pclogt:gt rats.

(E) Venn diagram shows the number of differentially expressed genes (DEGs) in the brain (754) and testis (88) or genes commonly expressed in both tissues (16) of $P c / o^{\mathrm{gt} / \mathrm{gt}}$ rats compared to $P c l o^{\mathrm{wt} / \mathrm{wt}}$ rats.

(F) Relative abundance of DEGs in Pclowt/gt $(\mathrm{HET})$ and $P c l o^{\mathrm{gt} / \mathrm{gt}}$ (KO) rat brain (top) and testis (bottom) vs wildtype (WT). DEGs that changed more in HET or more in KO vs WT are shown in red and light blue, respectively (log2-fold change $>1$ or $<-1$; FDR $<0.05$ ). Genes that changed comparably in abundance in both HET and KO but were differentially expressed relative to WT are shown in dark blue (log2-fold change $>1$ or $<-1$; FDR $<0.05$ ). Note, that the Pclo mutation affected more changes in the brain vs testis transcriptome.

(G) Fold change in relative brain (left) and testis (right) transcript abundance (Log2 FPKM values) in $P c l o^{\mathrm{wt} / \mathrm{gt}}$ and $P c \mathrm{O}^{\mathrm{gt} / \mathrm{gt}}$ rats vs $P c l o^{\mathrm{wt} / \mathrm{wt}}$ rats. DEGs are shown in red (increased abundance) and blue (decreased abundance), respectively (log2-fold change $>1$ or $<-1$; FDR $<0.05$ ). Note, the decreased Gabra6 and Gabra3 abundance in brain and testis, respectively, in both Pclo ${ }^{\mathrm{wt} / \mathrm{gt}}$ and $\mathrm{Pcl} \mathrm{O}^{\mathrm{gt} / \mathrm{gt}} \mathrm{rats}$.

Figure 5. Piccolo deficiency disrupts synaptic transmission and gonadotropin responsive gene sets

(A) Ontology of DEGs in $P c l o^{\text {gt/gt }}$ vs $P c / 0^{\text {gt/gt }}$ rat brains. Mean relative abundance of 80 synaptic transmission GO genes in $P c l o^{\text {gt/gt }}$ vs $P c l o^{\text {wt/wt }}$ rat brains (log2-fold change $>1$ or $<-1$; FDR $<0.05$ ).

(B) Gene Ontology gene enrichment pathway cluster analysis in $P c / o^{\text {wt } / \mathrm{wt}}$ vs $P c l o^{\mathrm{gt} / \mathrm{gt}}$ rat brains identified misregulated clusters for Hormonal Secretion (blue circle \& box) and Synaptic Transmission (Red Circle \& box) GO gene sets. 
(C) Quantification of the average number of GnRH positive neurons per section within the POA, revealing that Pclo-deficiency does not affect the number of $\mathrm{GnRH}$ neurons within the preoptic area (POA).

(D) High magnification images of GnRH positive neurons in $P c l o^{\mathrm{wt} / \mathrm{wt}} \mathrm{vs} P c / 0^{\mathrm{gt} / \mathrm{gt}}$ rat brains (Scale bars $=10 \mu \mathrm{m})$.

(E) Overlap between DEGs in Pclogt/gt rat testes and genes regulated by gonadotropins in rat testes[36]; FSH, Follicle Stimulating Hormone; LH, Luteinizing Hormone, T, Testosterone (log2-fold change $>1$ or $<-1$; FDR $<0.05$ ).

(F) Scatter plots of DEGs in $\mathrm{Pclo} \mathrm{gt}^{\mathrm{gt}} \mathrm{gt}$ rat testes and genes regulated by gonadotropins in rat testes [36].

Figure 6. Dominant neurotransmission and recessive reproductive behavior traits in Pclo mutant rats.

(A) Top: Seizure rates recorded in Pclowt:wt,$P c l o^{\text {wt:gt }}$ and $P c l o^{\text {gt:gt }}$ rats ( $\mathrm{n}=4$ rats/genotype). $\mathrm{p}<0.001$ for Pclowt:wt vs. Pclo ${ }^{\text {wt:gt }}$ or Pclogt:gt rats; $\mathrm{p}=0.1$ for Pclowt:gt vs. Pclogt:gt rats. Bottom: Representative EEG tracings recorded in $P c l o^{\text {wt:wt }}, P c l o^{\text {wt:gt }}$ and $P c l o^{\text {gt:gt }}$ rat brains.

(B) Altered social behavior in mutant $P$ clo rats. Time lapse frames showing an agitated $P c / o^{\mathrm{gt} / \mathrm{gt}}$ male lunging defensively at a $P c l o^{\text {wt/wt }}$ female rat. Similar aggressive behavior was not observed in Pclo ${ }^{\mathrm{wt} / \mathrm{gt}}$ or $\mathrm{Pclo} \mathrm{ot}^{\mathrm{wt} / \mathrm{wt}}$ rats.

Figure 7. Piccolo deficiency RNA endophenotypes link to depression gene profiles

(A) Cluster Analysis of differentially expressed genes (DEGs) in Pclowt:wt (WT), Pclowt:gt (HET) and Pclogt:gt (KO) rats.

(B) DEGs in Pclogt:gt vs Pclowt:wt $(\mathrm{KO} / \mathrm{Wt}$ ) rat brains are among major loci identified by human GWAS as MDD risk factors.

(C) Dysregulated genes in Pclo-KO versus Wt depressed rats. Note the significance level of correlated genes.

(D) Comparison between DEGs in depressed vs normal wt rat neurons and DEGs in Pclo-KO vs PcloWt rat brains. Red dots are showing a similar pattern of expression (rho $>0.3$ ).

(E) Gabra6 as prominent gene dysregulated in Pclo-KO rat brains is not detected in Pituitary and Hypothalamus of depressed rats (top). Depression-related marker Tph2 shown in comparison (bottom). 


\section{REFERENCES}

1. Kasman AM, Del Giudice F, Eisenberg ML. New insights to guide patient care: the bidirectional relationship between male infertility and male health. Fertil Steril. 2020. doi: 10.1016/j.fertnstert.2020.01.002. PubMed PMID: 32089256.

2. Chen P, Hong W. Neural Circuit Mechanisms of Social Behavior. Neuron. 2018;98(1):16-30. doi: 10.1016/j.neuron.2018.02.026. PubMed PMID: 29621486; PubMed Central PMCID: PMCPMC6028944.

3. Sokolowski K, Corbin JG. Wired for behaviors: from development to function of innate limbic system circuitry. Front Mol Neurosci. 2012;5:55. doi: 10.3389/fnmol.2012.00055. PubMed PMID: 22557946; PubMed Central PMCID: PMCPMC3337482.

4. Giordano M, Guemes M, Lopez-Arias V, Paredes RG. Socio-sexual behavior in male rats after lesions of the dorsolateral tegmentum. Physiol Behav. 1998;65(1):89-94. PubMed PMID: 9811370.

5. Santoru F, Berretti R, Locci A, Porcu P, Concas A. Decreased allopregnanolone induced by hormonal contraceptives is associated with a reduction in social behavior and sexual motivation in female rats. Psychopharmacology (Berl). 2014;231(17):3351-64. doi: 10.1007/s00213-0143539-9. PubMed PMID: 24728651.

6. Petrulis A. Chemosignals and hormones in the neural control of mammalian sexual behavior. Front Neuroendocrinol. 2013;34(4):255-67. doi: 10.1016/j.yfrne.2013.07.007. PubMed PMID: 23911848.

7. Petrulis A. Chemosignals, hormones and mammalian reproduction. Horm Behav. 2013;63(5):723-41. doi: 10.1016/j.yhbeh.2013.03.011. PubMed PMID: 23545474; PubMed Central PMCID: PMCPMC3667964.

8. Gibbs RA, Weinstock GM, Metzker ML, Muzny DM, Sodergren EJ, Scherer S, et al. Genome sequence of the Brown Norway rat yields insights into mammalian evolution. Nature. 2004;428(6982):493-521. doi: 10.1038/nature02426. PubMed PMID: 15057822.

9. Matzuk MM, Lamb DJ. The biology of infertility: research advances and clinical challenges. Nat Med. 2008;14(11):1197-213. doi: 10.1038/nm.f.1895. PubMed PMID: 18989307; PubMed Central PMCID: PMCPMC3786590.

10. Berridge KC, Kringelbach ML. Pleasure systems in the brain. Neuron. 2015;86(3):646-64. doi: 10.1016/j.neuron.2015.02.018. PubMed PMID: 25950633; PubMed Central PMCID: PMCPMC4425246.

11. Coria-Avila GA, Manzo J, Garcia LI, Carrillo P, Miquel M, Pfaus JG. Neurobiology of social attachments. Neurosci Biobehav Rev. 2014;43:173-82. doi: 10.1016/j.neubiorev.2014.04.004. PubMed PMID: 24769402.

12. Maclean PD. Some psychiatric implications of physiological studies on frontotemporal portion of limbic system (visceral brain). Electroencephalogr Clin Neurophysiol. 1952;4(4):407-18. PubMed PMID: 12998590.

13. Phelps EA, LeDoux JE. Contributions of the amygdala to emotion processing: from animal models to human behavior. Neuron. 2005;48(2):175-87. doi: 10.1016/j.neuron.2005.09.025. PubMed PMID: 16242399.

14. Vigdal TJ, Kaufman CD, Izsvak Z, Voytas DF, Ivics Z. Common physical properties of DNA affecting target site selection of sleeping beauty and other Tc1/mariner transposable elements. J Mol Biol. 2002;323(3):441-52. PubMed PMID: 12381300. 
15. Izsvak Z, Ivics Z, Plasterk RH. Sleeping Beauty, a wide host-range transposon vector for genetic transformation in vertebrates. J Mol Biol. 2000;302(1):93-102. doi: 10.1006/jmbi.2000.4047. PubMed PMID: 10964563.

16. Ivics Z, Hackett PB, Plasterk RH, Izsvak Z. Molecular reconstruction of Sleeping Beauty, a Tc1-like transposon from fish, and its transposition in human cells. Cell. 1997;91(4):501-10. PubMed PMID: 9390559.

17. Izsvak Z, Frohlich J, Grabundzija I, Shirley JR, Powell HM, Chapman KM, et al. Generating knockout rats by transposon mutagenesis in spermatogonial stem cells. Nat Methods. 2010;7(6):443-5. Epub 2010/05/18. doi: 10.1038/nmeth.1461. PubMed PMID: 20473302; PubMed Central PMCID: PMC2886193.

18. Ahmed MY, Chioza BA, Rajab A, Schmitz-Abe K, Al-Khayat A, Al-Turki S, et al. Loss of PCLO function underlies pontocerebellar hypoplasia type III. Neurology. 2015;84(17):174550. doi: 10.1212/WNL.0000000000001523. PubMed PMID: 25832664; PubMed Central PMCID: PMCPMC4424132.

19. Choi KH, Higgs BW, Wendland JR, Song J, McMahon FJ, Webster MJ. Gene expression and genetic variation data implicate PCLO in bipolar disorder. Biol Psychiatry. 2011;69(4):353-9. Epub 2010/12/28. doi: 10.1016/j.biopsych.2010.09.042. PubMed PMID: 21185011; PubMed Central PMCID: PMC3278480.

20. Sullivan PF, de Geus EJ, Willemsen G, James MR, Smit JH, Zandbelt T, et al. Genome-wide association for major depressive disorder: a possible role for the presynaptic protein piccolo. Mol Psychiatry. 2009;14(4):359-75. Epub 2008/12/10. doi: 10.1038/mp.2008.125. PubMed PMID: 19065144; PubMed Central PMCID: PMC2717726.

21. Lorenzetti D, Poirier C, Zhao M, Overbeek PA, Harrison W, Bishop CE. A transgenic insertion on mouse chromosome 17 inactivates a novel immunoglobulin superfamily gene potentially involved in sperm-egg fusion. Mamm Genome. 2014;25(3-4):141-8. doi: 10.1007/s00335-0139491-x. PubMed PMID: 24275887.

22. Alers S, Wesselborg S, Stork B. ATG13: Just a companion, or an executor of the autophagic program? Autophagy. 2014;10(6):944-56. doi: 10.4161/auto.28987. PubMed PMID: 24879146.

23. Funakoshi T, Matsuura A, Noda T, Ohsumi Y. Analyses of APG13 gene involved in autophagy in yeast, Saccharomyces cerevisiae. Gene. 1997;192(2):207-13. PubMed PMID: 9224892.

24. Suttangkakul A, Li F, Chung T, Vierstra RD. The ATG1/ATG13 protein kinase complex is both a regulator and a target of autophagic recycling in Arabidopsis. Plant Cell. 2011;23(10):376179. doi: 10.1105/tpc.111.090993. PubMed PMID: 21984698; PubMed Central PMCID: PMCPMC3229148.

25. Cases-Langhoff C, Voss B, Garner AM, Appeltauer U, Takei K, Kindler S, et al. Piccolo, a novel $420 \mathrm{kDa}$ protein associated with the presynaptic cytomatrix. Eur J Cell Biol. 1996;69(3):214-23. PubMed PMID: 8900486.

26. Rupprecht R, Papadopoulos V, Rammes G, Baghai TC, Fan J, Akula N, et al. Translocator protein $(18 \mathrm{kDa})(\mathrm{TSPO})$ as a therapeutic target for neurological and psychiatric disorders. Nat Rev Drug Discov. 2010;9(12):971-88. doi: 10.1038/nrd3295. PubMed PMID: 21119734.

27. Lian J, Watts R, Quiroga AD, Beggs MR, Alexander RT, Lehner R. Ces1d deficiency protects against high-sucrose diet-induced hepatic triacylglycerol accumulation. J Lipid Res. 2019;60(4):880-91. doi: 10.1194/j1r.M092544. PubMed PMID: 30737251; PubMed Central PMCID: PMCPMC6446703. 
28. Spiegelstein O, Cabrera RM, Bozinov D, Wlodarczyk B, Finnell RH. Folate-regulated changes in gene expression in the anterior neural tube of folate binding protein-1 (Folbp1)-deficient murine embryos. Neurochem Res. 2004;29(6):1105-12. PubMed PMID: 15176467.

29. Yang Y, Luo J, Yu D, Zhang T, Lin Q, Li Q, et al. Vitamin A Promotes Leydig Cell Differentiation via Alcohol Dehydrogenase 1. Front Endocrinol (Lausanne). 2018;9:644. doi: 10.3389/fendo.2018.00644. PubMed PMID: 30420837; PubMed Central PMCID: PMCPMC6216111.

30. Temple JL, Wray S. Developmental changes in GABA receptor subunit composition within the gonadotrophin-releasing hormone-1 neuronal system. J Neuroendocrinol. 2005;17(9):591-9. doi: 10.1111/j.1365-2826.2005.01348.x. PubMed PMID: 16101898.

31. Carmel PW, Araki S, Ferin M. Pituitary stalk portal blood collection in rhesus monkeys: evidence for pulsatile release of gonadotropin-releasing hormone $(\mathrm{GnRH})$. Endocrinology. 1976;99(1):243-8. doi: 10.1210/endo-99-1-243. PubMed PMID: 820547.

32. Yoon H, Enquist LW, Dulac C. Olfactory inputs to hypothalamic neurons controlling reproduction and fertility. Cell. 2005;123(4):669-82. doi: 10.1016/j.cell.2005.08.039. PubMed PMID: 16290037.

33. Boehm U, Zou Z, Buck LB. Feedback loops link odor and pheromone signaling with reproduction. Cell. 2005;123(4):683-95. doi: 10.1016/j.cell.2005.09.027. PubMed PMID: 16290036.

34. Watanabe M, Fukuda A, Nabekura J. The role of GABA in the regulation of GnRH neurons. Front Neurosci. 2014;8:387. doi: 10.3389/fnins.2014.00387. PubMed PMID: 25506316; PubMed Central PMCID: PMCPMC4246667.

35. Herbison AE, Moenter SM. Depolarising and hyperpolarising actions of GABA(A) receptor activation on gonadotrophin-releasing hormone neurones: towards an emerging consensus. J Neuroendocrinol. 2011;23(7):557-69. doi: 10.1111/j.1365-2826.2011.02145.x. PubMed PMID: 21518033; PubMed Central PMCID: PMCPMC3518440.

36. Zhou W, Bolden-Tiller OU, Shetty G, Shao SH, Weng CC, Pakarinen P, et al. Changes in gene expression in somatic cells of rat testes resulting from hormonal modulation and radiationinduced germ cell depletion. Biol Reprod. 2010;82(1):54-65. doi: 10.1095/biolreprod.109.078048. PubMed PMID: 19684331; PubMed Central PMCID: PMCPMC2802113.

37. True C, Grove KL, Smith MS. Beyond Leptin: Emerging Candidates for the Integration of Metabolic and Reproductive Function during Negative Energy Balance. Front Endocrinol (Lausanne). 2011;2:53. doi: 10.3389/fendo.2011.00053. PubMed PMID: 22645510; PubMed Central PMCID: PMCPMC3355832.

38. Piet R, Fraissenon A, Boehm U, Herbison AE. Estrogen permits vasopressin signaling in preoptic kisspeptin neurons in the female mouse. J Neurosci. 2015;35(17):6881-92. doi: 10.1523/JNEUROSCI.4587-14.2015. PubMed PMID: 25926463.

39. Luquet $S$, Magnan $C$. The central nervous system at the core of the regulation of energy homeostasis. Front Biosci (Schol Ed). 2009;1:448-65. PubMed PMID: 19482713.

40. Bosch OJ. Maternal aggression in rodents: brain oxytocin and vasopressin mediate pup defence. Philos Trans R Soc Lond B Biol Sci. 2013;368(1631):20130085. doi: 10.1098/rstb.2013.0085. PubMed PMID: 24167315; PubMed Central PMCID: PMCPMC3826214.

41. Dunn HA, Walther C, Yuan GY, Caetano FA, Godin CM, Ferguson SS. Role of SAP97 in the regulation of 5-HT2AR endocytosis and signaling. Mol Pharmacol. 2014;86(3):275-83. doi: 10.1124/mol.114.093476. PubMed PMID: 24989932. 
42. Gereau RWt, Heinemann SF. Role of protein kinase C phosphorylation in rapid desensitization of metabotropic glutamate receptor 5. Neuron. 1998;20(1):143-51. PubMed PMID: 9459450.

43. Wray NR, Ripke S, Mattheisen M, Trzaskowski M, Byrne EM, Abdellaoui A, et al. Genomewide association analyses identify 44 risk variants and refine the genetic architecture of major depression. Nat Genet. 2018;50(5):668-81. doi: 10.1038/s41588-018-0090-3. PubMed PMID: 29700475; PubMed Central PMCID: PMCPMC5934326.

44. Wang Y, Jiang H, Meng H, Lu J, Li J, Zhang X, et al. Genome-wide transcriptome analysis of hippocampus in rats indicated that TLR/NLR signaling pathway was involved in the pathogenisis of depressive disorder induced by chronic restraint stress. Brain Res Bull. 2017;134:195-204. doi: 10.1016/j.brainresbull.2017.07.021. PubMed PMID: 28780410.

45. Inoue A, Akiyoshi J, Muronaga M, Masuda K, Aizawa S, Hirakawa H, et al. Association of TMEM132D, COMT, and GABRA6 genotypes with cingulate, frontal cortex and hippocampal emotional processing in panic and major depressive disorder. Int J Psychiatry Clin Pract. 2015;19(3):192-200. doi: 10.3109/13651501.2015.1043133. PubMed PMID: 25974322.

46. Mendoza-Topaz C, Urra F, Barria R, Albornoz V, Ugalde D, Thomas U, et al. DLGS97/SAP97 is developmentally upregulated and is required for complex adult behaviors and synapse morphology and function. J Neurosci. 2008;28(1):304-14. doi: 10.1523/JNEUROSCI.439507.2008. PubMed PMID: 18171947; PubMed Central PMCID: PMCPMC4656021.

47. Mukherjee K, Yang X, Gerber SH, Kwon HB, Ho A, Castillo PE, et al. Piccolo and bassoon maintain synaptic vesicle clustering without directly participating in vesicle exocytosis. Proc Natl Acad Sci U S A. 2010;107(14):6504-9. doi: 10.1073/pnas.1002307107. PubMed PMID: 20332206; PubMed Central PMCID: PMCPMC2851964.

48. Hieke N, Loffler AS, Kaizuka T, Berleth N, Bohler P, Driessen S, et al. Expression of a ULK1/2 binding-deficient ATG13 variant can partially restore autophagic activity in ATG13-deficient cells. Autophagy. 2015;11(9):1471-83. doi: 10.1080/15548627.2015.1068488. PubMed PMID: 26213203; PubMed Central PMCID: PMCPMC4590663.

49. Ferreira RC, Pan-Hammarstrom Q, Graham RR, Gateva V, Fontan G, Lee AT, et al. Association of IFIH1 and other autoimmunity risk alleles with selective IgA deficiency. Nat Genet. 2010;42(9):777-80. doi: 10.1038/ng.644. PubMed PMID: 20694011.

50. Bronson PG, Chang D, Bhangale T, Seldin MF, Ortmann W, Ferreira RC, et al. Common variants at PVT1, ATG13-AMBRA1, AHI1 and CLEC16A are associated with selective IgA deficiency. Nat Genet. 2016;48(11):1425-9. doi: 10.1038/ng.3675. PubMed PMID: 27723758; PubMed Central PMCID: PMCPMC5086090.

51. Kaizuka T, Mizushima N. Atg13 is essential for autophagy and cardiac development in mice. Molecular and Cellular Biology. 2016;36(4):585-95. Epub February 2016.

52. Henderson LP. Steroid modulation of GABAA receptor-mediated transmission in the hypothalamus: effects on reproductive function. Neuropharmacology. 2007;52(7):1439-53. doi: 10.1016/j.neuropharm.2007.01.022. PubMed PMID: 17433821; PubMed Central PMCID: PMCPMC1985867.

53. Ackermann F, Schink KO, Bruns C, Izsvák Z, Hamra FK, Rosenmund C, et al. Critical role for piccolo in synaptic vesicle retrieval. eLife. 2019;8:e46629 DOI: 10.7554/eLife.46629.

54. Falck J, Bruns C, Hoffmann-Conaway S, Straub I, Plautz EJ, Orlando M, et al. Loss of Piccolo function in rats induces cerebellar network dysfunction and Pontocerebellar Hypoplasia type 3like phenotypes. J Neurosci. 2020. doi: 10.1523/JNEUROSCI.2316-19.2020. PubMed PMID: 32122952. 
55. Howard DM, Adams MJ, Shirali M, Clarke TK, Marioni RE, Davies G, et al. Genome-wide association study of depression phenotypes in UK Biobank identifies variants in excitatory synaptic pathways. Nat Commun. 2018;9(1):1470. doi: 10.1038/s41467-018-03819-3. PubMed PMID: 29662059; PubMed Central PMCID: PMCPMC5902628.

56. Woudstra S, Bochdanovits Z, van Tol MJ, Veltman DJ, Zitman FG, van Buchem MA, et al. Piccolo genotype modulates neural correlates of emotion processing but not executive functioning. Transl Psychiatry. 2012;2:e99. Epub 2012/07/27. doi: 10.1038/tp.2012.29. PubMed PMID: 22832909; PubMed Central PMCID: PMC3337071.

57. Woudstra S, van Tol MJ, Bochdanovits Z, van der Wee NJ, Zitman FG, van Buchem MA, et al. Modulatory effects of the piccolo genotype on emotional memory in health and depression. PLoS One. 2013;8(4):e61494. doi: 10.1371/journal.pone.0061494. PubMed PMID: 23620758; PubMed Central PMCID: PMCPMC3631241.

58. Waites CL, Leal-Ortiz SA, Okerlund N, Dalke H, Fejtova A, Altrock WD, et al. Bassoon and Piccolo maintain synapse integrity by regulating protein ubiquitination and degradation. EMBO J. 2013;32(7):954-69. doi: 10.1038/emboj.2013.27. PubMed PMID: 23403927; PubMed Central PMCID: PMCPMC3616282.

59. Homanics GE, Ferguson C, Quinlan JJ, Daggett J, Snyder K, Lagenaur C, et al. Gene knockout of the alpha6 subunit of the gamma-aminobutyric acid type A receptor: lack of effect on responses to ethanol, pentobarbital, and general anesthetics. Mol Pharmacol. 1997;51(4):58896. PubMed PMID: 9106623.

60. Korpi ER, Koikkalainen P, Vekovischeva OY, Makela R, Kleinz R, Uusi-Oukari M, et al. Cerebellar granule-cell-specific GABAA receptors attenuate benzodiazepine-induced ataxia: evidence from alpha 6-subunit-deficient mice. Eur J Neurosci. 1999;11(1):233-40. PubMed PMID: 9987027.

61. Giniatullina A, Maroteaux G, Geerts CJ, Koopmans B, Loos M, Klaassen R, et al. Functional characterization of the PCLO p.Ser4814Ala variant associated with major depressive disorder reveals cellular but not behavioral differences. Neuroscience. 2015;300:518-38. doi: 10.1016/j.neuroscience.2015.05.047. PubMed PMID: 26045179.

62. Anders S, Huber W. Differential expression analysis for sequence count data. Genome Biol. 2010;11(10):R106. doi: 10.1186/gb-2010-11-10-r106. PubMed PMID: 20979621; PubMed Central PMCID: PMCPMC3218662.

63. Ayadi A, Birling MC, Bottomley J, Bussell J, Fuchs H, Fray M, et al. Mouse large-scale phenotyping initiatives: overview of the European Mouse Disease Clinic (EUMODIC) and of the Wellcome Trust Sanger Institute Mouse Genetics Project. Mamm Genome. 2012;23(910):600-10. Epub 2012/09/11. doi: 10.1007/s00335-012-9418-y. PubMed PMID: 22961258; PubMed Central PMCID: PMC3463797. 


\section{Supporting Information}

S1 Fig. Predicted proteins produced in Sleeping Beauty 6-geo genetrap rat strains. Exon sequences predicted to be excluded $(\Delta)$ from mRNAs encoding truncated polypeptides (aa) generated by imposed splicing to the genetrap transposon are shown below respective wildtype proteins for 17 of the 18 mutant rat strains screened for effects on reproduction. Transposon insertion within intron 2 of Rgs22 is not predicted to truncate the Rgs22 open reading frame due to its intronic genetrap cassette inserting in the $3^{\prime}$ to $5^{\prime}$ orientation. See: S1 Table for full amino acid sequences of the 17 predicted truncated proteins encoded by respective trapped genes, which contain additional epitopes of either 3, 24 or 1319 ( $\beta$-GEO) amino acids derived from the genetrap construct.

TM, Transmembrane domain; AAA, ATPase Associated with a variety of cellular activities; GS, GS Motif; L27, domain in receptor targeting proteins Lin-2 and Lin-7; MN-PEST, Polyubiquitination (PEST) $\mathrm{N}$-terminal domain of MAGUK; PDZ, Domain present in PSD-95; $\beta$-TrCP, D domain of beta-TrCP; FBOX, A Receptor for Ubiquitination Targets; Dlg, and ZO-1/2; SH3, Src homology 3 domain; GuKc, Guanylate kinase homologue; CC, coil coil region; KAZAL, Kazal type serine protease inhibitors; IGc2, Immunoglobulin C-2 Type; Lg-Ch-Bd, Ligated ion channel L-glutamate- and glycine-binding site; ZnF_C3H1, Zinc Finger Domain; STYKc, Protein kinase; unclassified specificity; C2, Protein kinase C conserved region 2 (CalB); UBCc, Ubiquitin-conjugating enzyme E2, catalytic domain homologue; UBA, Ubiquitin associated domain; RWD, domain in RING finger and WD repeat containing proteins and DEXDc-like helicases subfamily related to the UBCC domain; PHD, PHD zinc finger; BROMO, bromo domain; PWWP, domain with conserved PWWP motif.

\section{S2 Fig. Gametogenesis defects in rats with gene-trap mutations}

(A) H\&E stained testis sections from wildtype and respective homozygous genetrap mutant rats. Scale bar, $100 \mu \mathrm{m}$.

(B) Immunofluorescence labeling of cells in wildtype and mutant Btrc ${ }^{\text {gt/gt }}$ rat testis sections using an antibody to $\mathrm{yH} 2 \mathrm{AX}$ and Hoechst 43332 dye as nuclear markers. Scale bar, $100 \mu \mathrm{m}$.

(C) H\&E stained ovarian sections from wildtype and respective homozygous genetrap mutant rats. Scale bar, $100 \mu \mathrm{m}$. 
S3 Fig. Gonadotropin Releasing Hormone (GnRH) signaling pathway genes are downregulated in the brain of mutant Piccolo rats.

(A) Panther Pathway finder analysis on down regulated Hormonal Secretion GO: gene sets identify GnRH signaling pathway as the prominent cluster of DEGs in Pclogt/gt vs $P c l o^{\text {wt } / \text { wt }}$ rat brains.

(B) Coronal brain sections from Pclo ${ }^{\mathrm{wt} / \mathrm{wt}}$ or $\mathrm{Pclo}^{\mathrm{gt} / \mathrm{gt}}$ postnatal day 100 rat brains immuno-stained with GnRH antibodies. Lower panel, 5x magnification of the preoptic area (POA) located in the boxed area reveal presence of somata and $\mathrm{GnRH}$ positive neuron processes flanking the third ventricle. Scale bars = upper panel $0.3 \mathrm{~cm}$, lower panel $1000 \mu \mathrm{m}$.

(C) Relative abundance of GnRH signaling pathway GO: gene set in $P c / o^{\mathrm{gt} / \mathrm{gt}}(\mathrm{KO})$ and $P c / o^{\mathrm{wt} / \mathrm{gt}}$ (HET) vs Pclo ${ }^{\mathrm{wt} / \mathrm{wt}}(\mathrm{WT})$ rat brains.

(D) KEGG pathway analysis predicts downregulated GnRH signaling pathways in Pclo ${ }^{\text {gt/gt }}$ rat brains vs Pclowt/wt rat brains. Note: See Panel C for official GnRH signaling pathway gene symbols; KEGG pathway analysis illustrates common gene acronyms.

\section{S4 Fig. Misregulated gene networks downstream of GnRH signaling.}

(A) Relative abundance of DEGs encoding G-Protein Coupled Receptors (GPCRs) involved in conducting GnRH signaling on gonadotropes GO: gene set components in Pclogt/gt (KO) and Pclowt/gt (Het) vs Pclowt/wt (WT) rat brains.

(B) Relative abundance of Calcium Signaling GO: gene set components in Pclo KO and HET vs WT rat brains. *Note, Dlgwt/gt mutant rats displayed altered behavior and reduced fecundity (see S4 Table). (C) Bar plots demonstrate relative FSH (left) and LH (center) concentrations in $\mathrm{Pclo}{ }^{\mathrm{wt} / \mathrm{wt}}$ and $\mathrm{Pclo}{ }^{\mathrm{gt} / \mathrm{gt}}$ rats determined by ELISA at two dilutions (5x and 10x) and three technical replicates. ELISA mean \pm SD absorbance values obtained from three animals (two Pclo ${ }^{\mathrm{wt} / \mathrm{wt}}$ and one Pclo $\mathrm{gt}^{\mathrm{gt}}$ ). Asterisks represent $p$-values obtained by t-test. Boxplot with jitters (right) is an alternative representation of $\mathrm{LH}$ and FSH levels analyzed together between $\mathrm{Pclo}^{\mathrm{wt} / \mathrm{wt}}$ vs $P c / 0^{\mathrm{gt} / \mathrm{gt}}$ rats. Asterisks represent $\mathrm{p}$-values obtained by Wilcox test. Each dot represents a replicate (biological/technical).

(D) Relative abundance of Gonadotropin Regulated Genes in Pclo KO vs WT rat testes (PCLO ko/wt) that are Repressed or Activated by FSH, Follicle Stimulating Hormone; LH, Luteinizing Hormone, T, Testosterone (Zhou et al., 2010). 
S1 Table. Gene Trap Mutations in Rat Strains Screened for Reproduction Phenotypes

S2 Table. Reproduction Phenotypes in Rats with Sleeping Beauty Gene Trap Mutations

S3 Table. Body, Testis and Epididymal Weights in Sleeping Beauty Mutant Rats

S4 Table. Mutant Rat Phenotypes in Current Study* Compared Across Species.

S5 Table. RNA Sequencing: Brain and Testes Transcriptomes Pclo Mutant Rats

S6 Table. Gene Ontology: Brain and Testes Transcriptomes Pclo Mutant Rats

S1 Video. Female WT \& Male WT Rats

S2 Video. Female Pclo KO \& Male WT Rats

S3 Video. Male Pclo KO \& Male WT Rats

S4 Video. Male WT \& Male WT Rats

S5 Video. Male WT \& Male Pclo HET Rats

S6 Video. Male Pclo KO \& Male Pclo WT Rats 


\section{Transfect Stem Spermatogonia with Sleeping Beauty}

$\beta$-Geo Gene Trap Transposon System

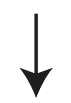

Select Recombinant Spermatogonial Library Enriched with Gene Traps in Protein Coding Genes

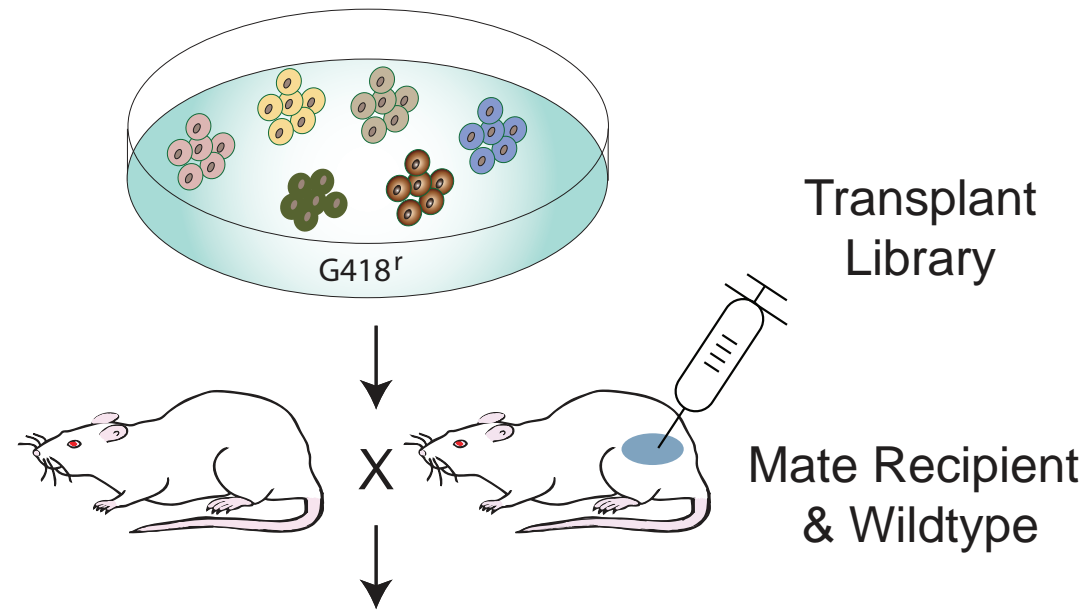

Produce Colony of Mutant Heterozygotes

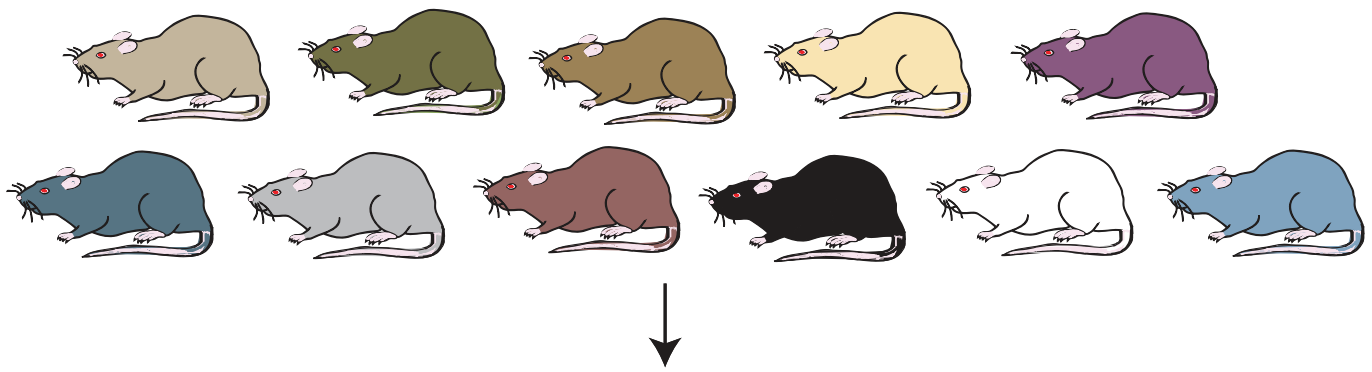

Define Trapped Genes in Each Mutant

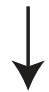

Breed Mutants to Screen for Reproduction Phenotypes 
A
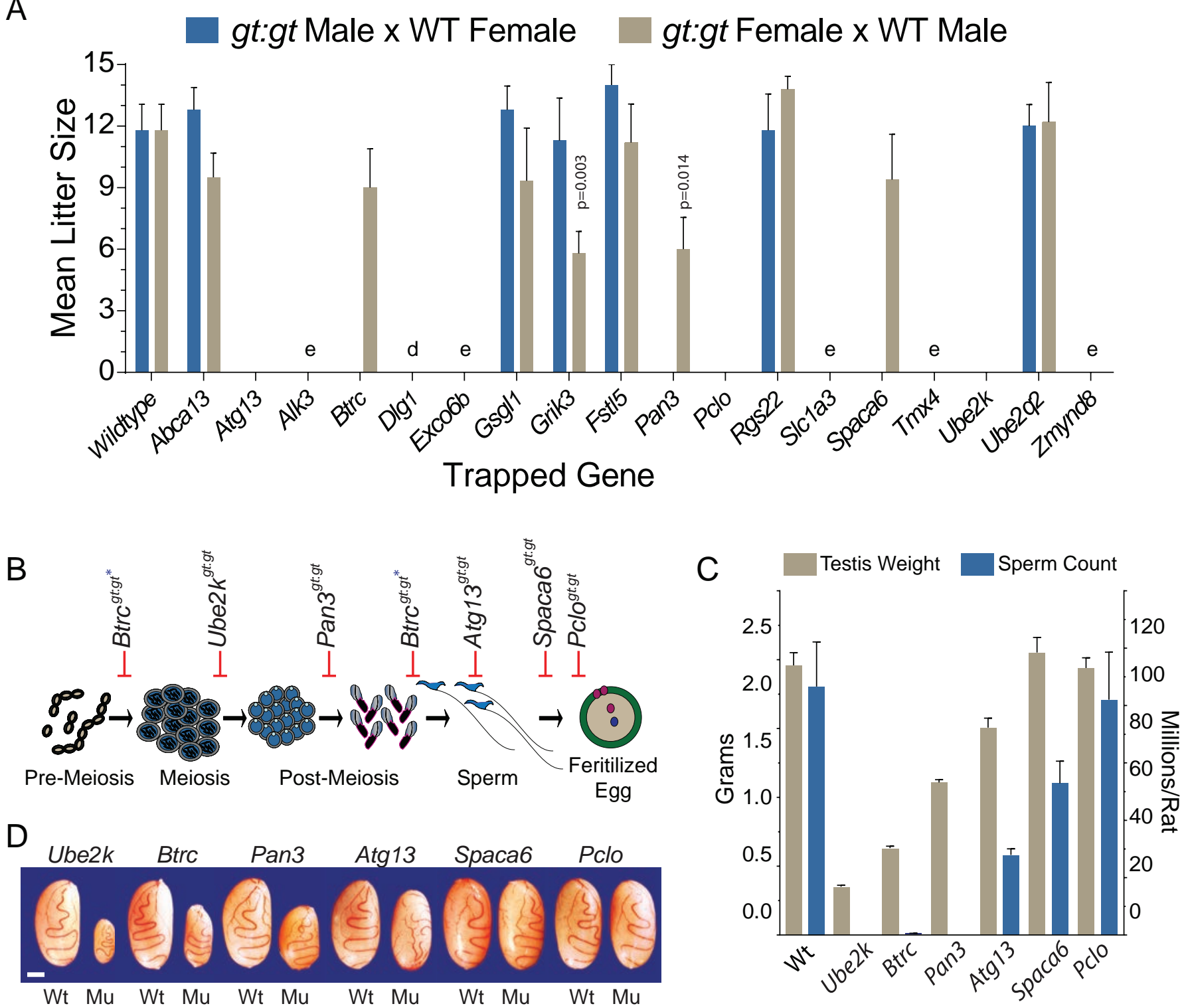

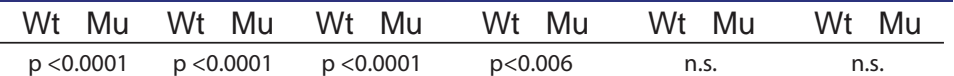

Homozygous Mutant Rat Strain 
A
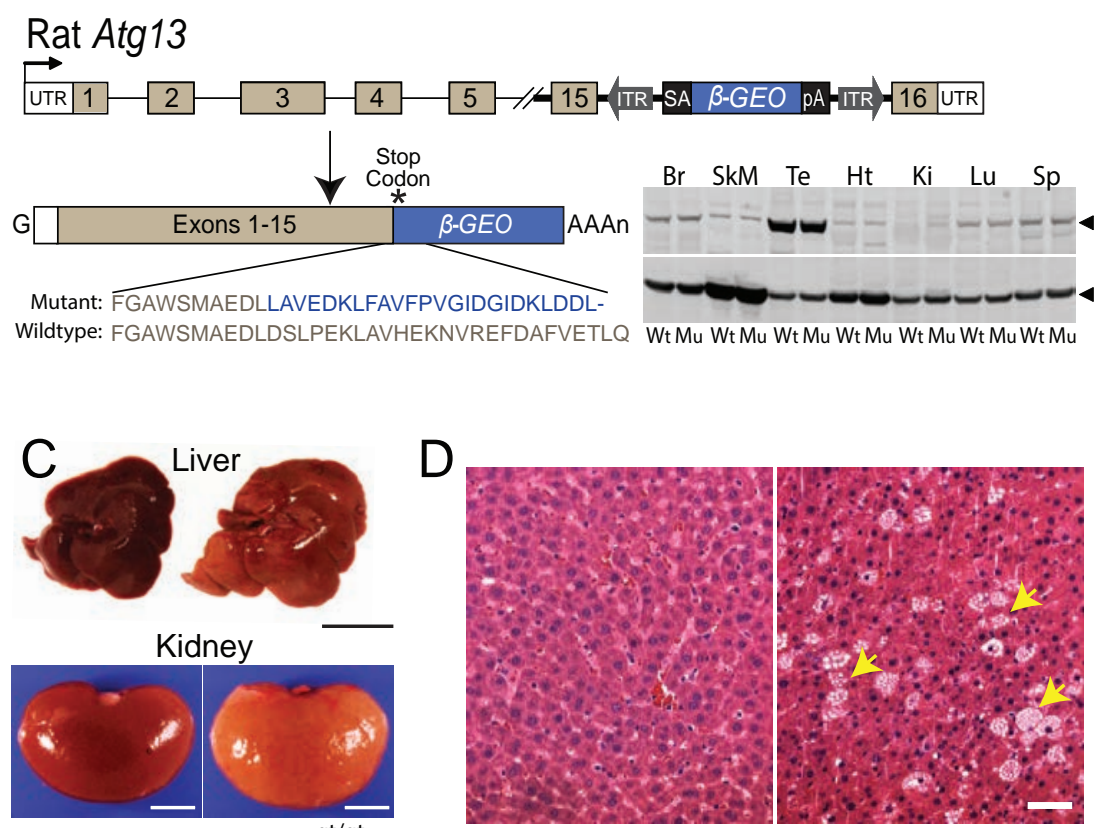

Wildtype $\quad$ ATG13 ${ }^{\mathrm{gt} / \mathrm{gt}}$

$\mathrm{F}$

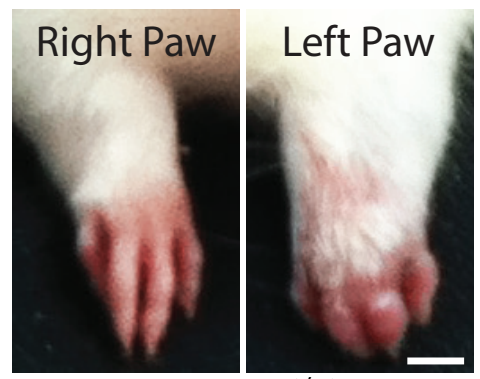

ATG13 $13^{\mathrm{gt} / \mathrm{gt}}$
Wildtype

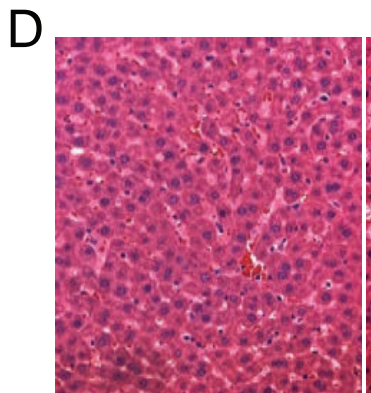

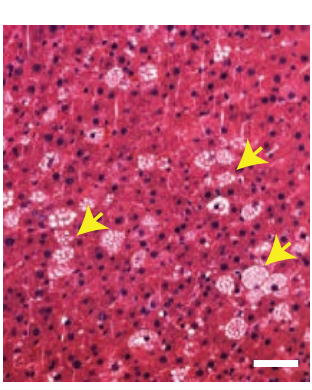

ATG13 $3^{\mathrm{gt} / \mathrm{gt}}$
$\mathrm{B}$

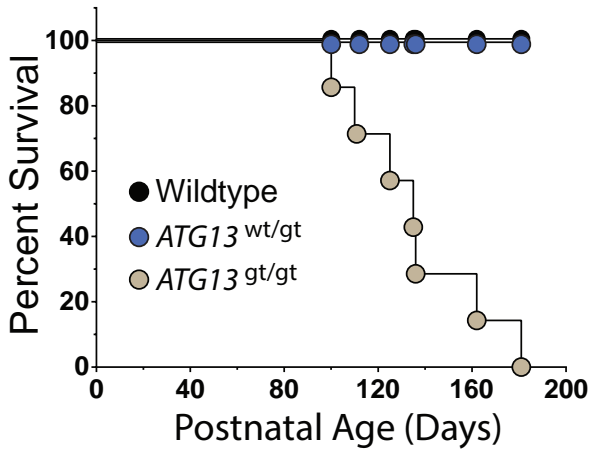

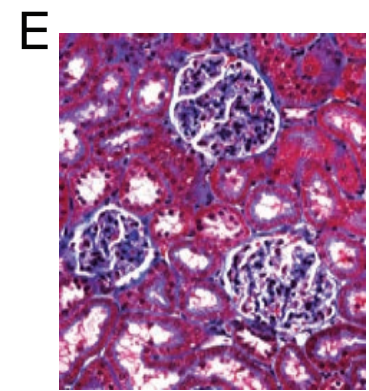

Wildtype

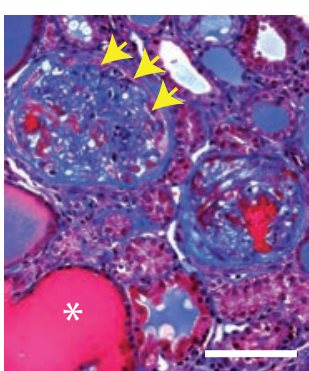

ATG13 ${ }^{\mathrm{gt} / \mathrm{gt}}$

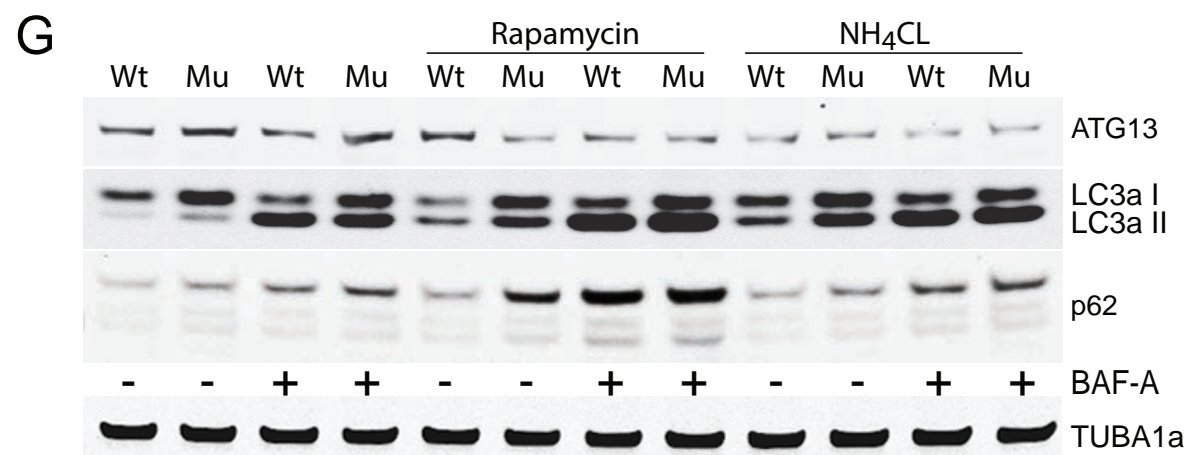


bioRxiv preprint doi: https://doi org/10.1101/405985; this version posted March 19,2020. The copyright holder for this preprint (which was not certified by peer review) is the author/funder, who has granted bioRxiv a license to display the preprint in perpetuity. It is made available under aCC-BY-NC-ND 4.0 International license.

A

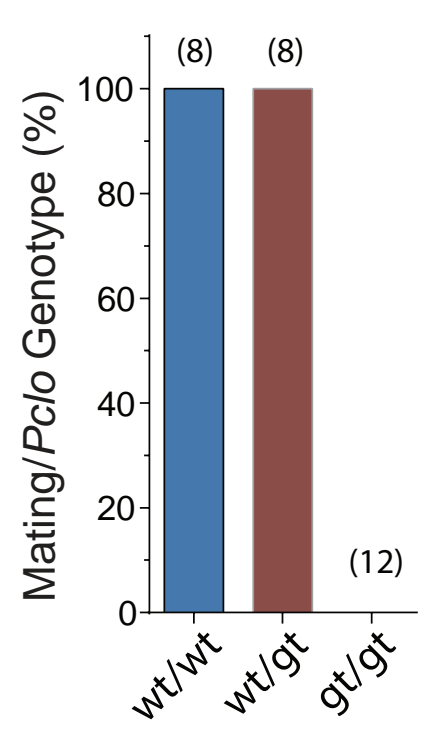

B

Figure 4

\section{Rat Pclo}
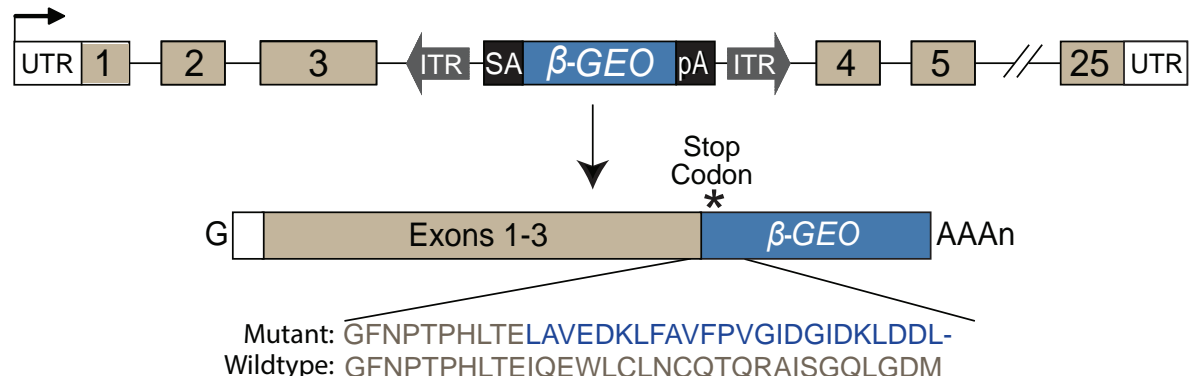

C

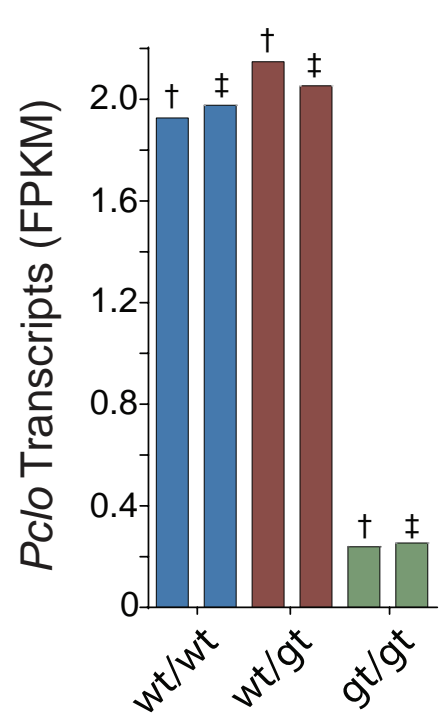

D

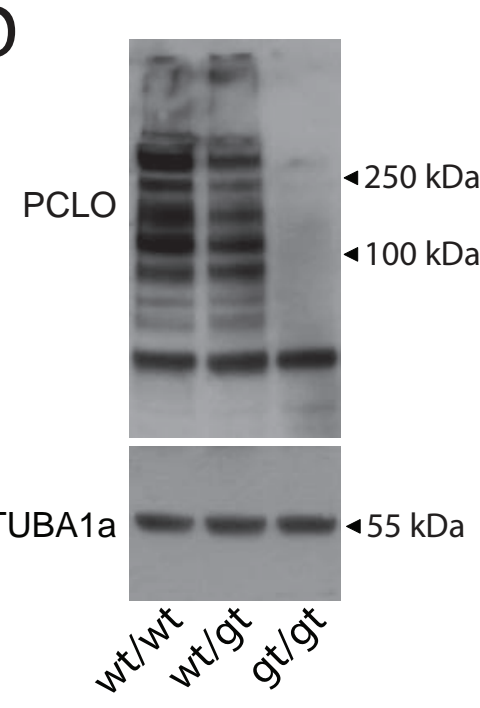

E

$\mathrm{Pclo}^{g t / g t}$ vs Pclo ${ }^{w t / w t}$

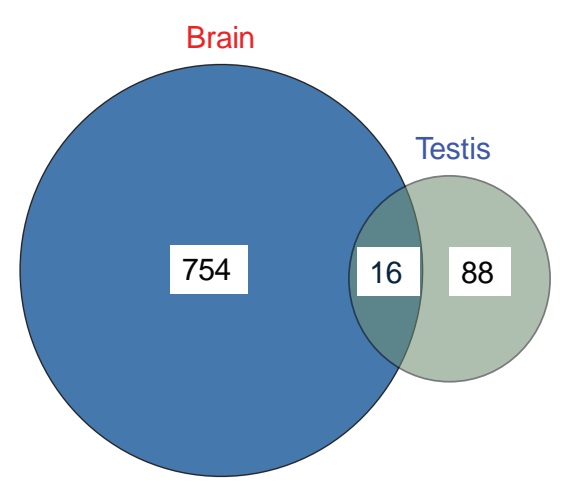

Mean Expression Level $>2$ Mean Fold Change $>2 \mid<-2$ E-FDR

$<0.05$

F

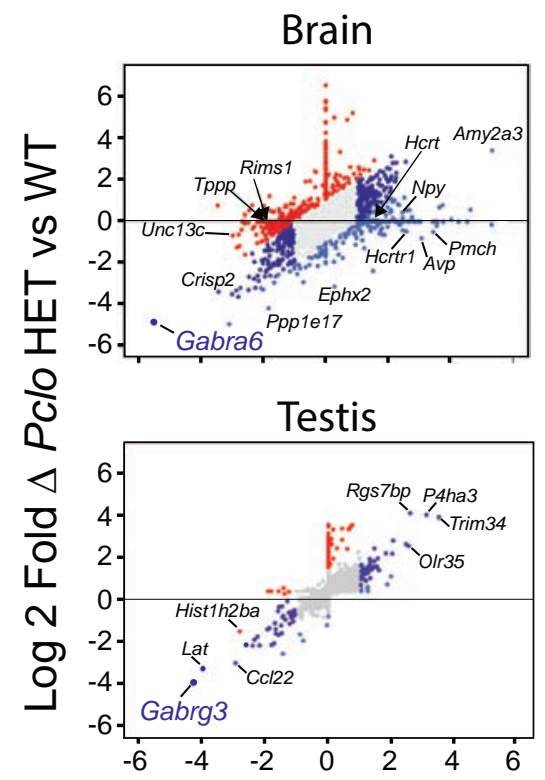

Log 2 Fold $\Delta$ Pclo KO vs WT

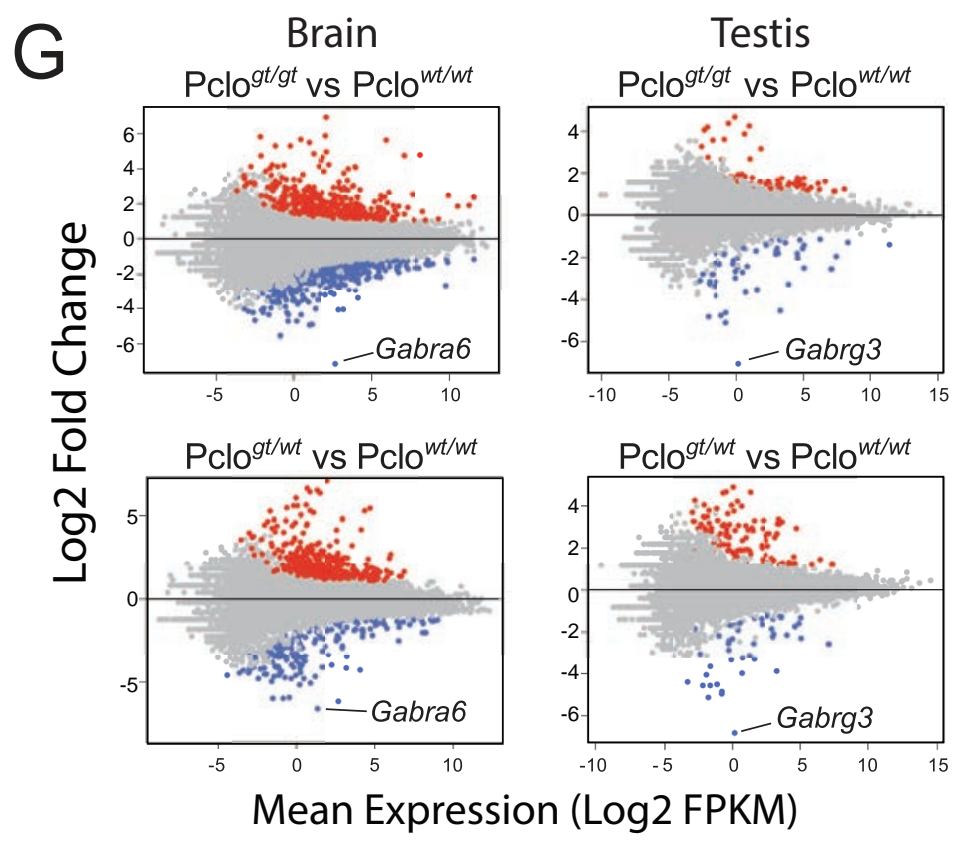


bioRxiv preprint doi: https://doi org/10.1101/405985; this version posted March 19, 2020. The copyright holder for this preprint (which was not certified by peer review) is the author/funder, who has granted bioRxiv a license to display the preprint in perpetuity. It is made available under aCC-BY-NC-ND 4.0 International license.

Figure 5

\section{A}

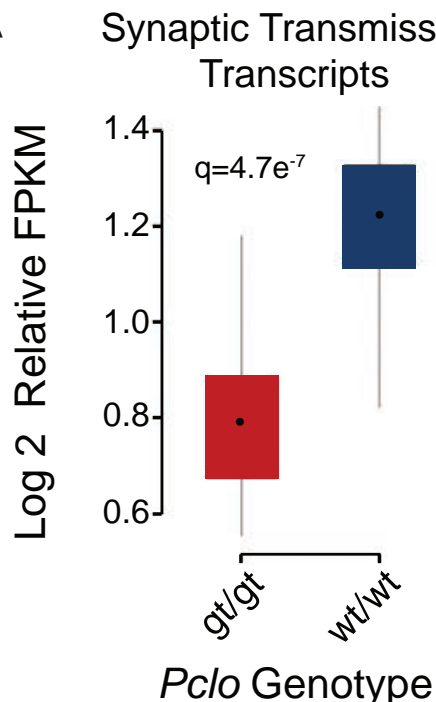

C

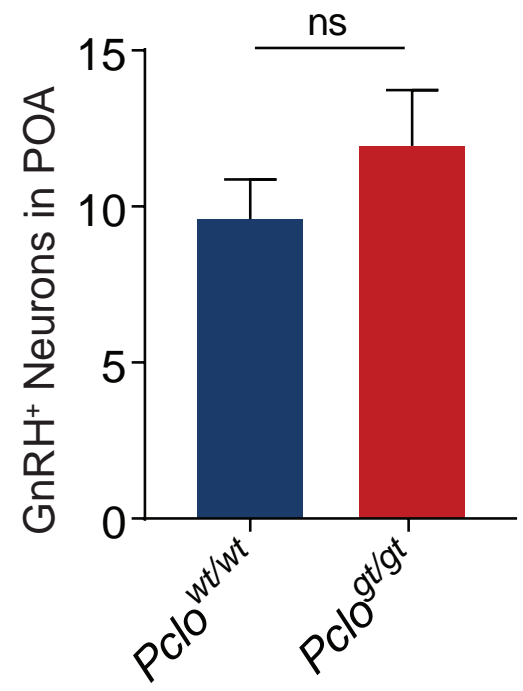

F

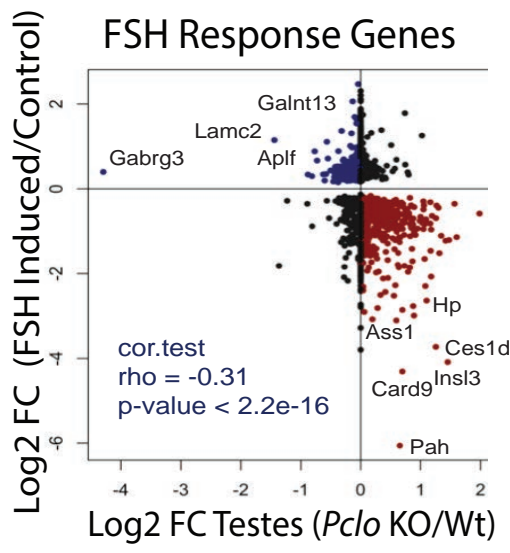

B Gene Ontology Gene Set Analysis Pclogt/gt vs. Pclowt/wt

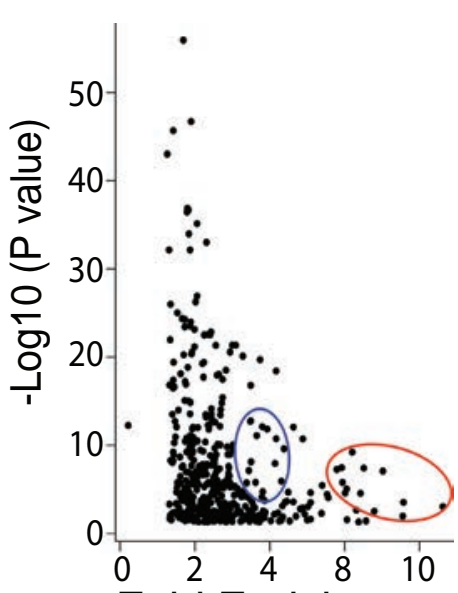

Synaptic Transmission Gene Sets Gamma-Aminobutyric Acid Signaling Pathway (GO:0007214)
Neurotransmitter Secretion Regulation (GO:0046928) Negative Regulation of Synaptic Transmission (GO:0050805) Drug Metabolic Process (GO:0017144)

Synaptic Transmission Regulation, Glutaminergic (GO:0051966) Long Term Neuronal Plasticity Regulation (GO:0048169)

Neurotransmitter Transport Regulation (GO:0051588)

\section{Hormone Secretion Gene Sets}

Positive Regulation of Hormone Secretion (GO:0046887)

Regulation of Peptide Hormone Secretion (GO:0090276)

Regulation of Hormone Secretion (GO:0046883)

Regulation of Hormone Levels (GO:0010817)

Response to Steroid Hormones (GO:0048545)

Response to Peptide Hormone (GO:0043434)

Response to Hormone (GO:0009725)

Cellular Response to Hormone Stimulus (GO:0032870)
$E$
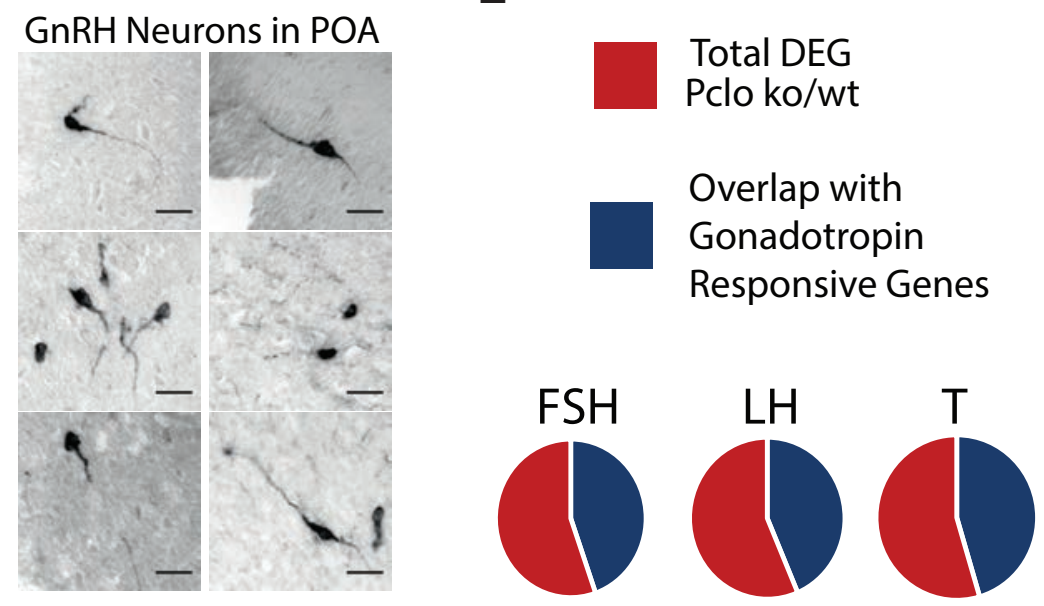

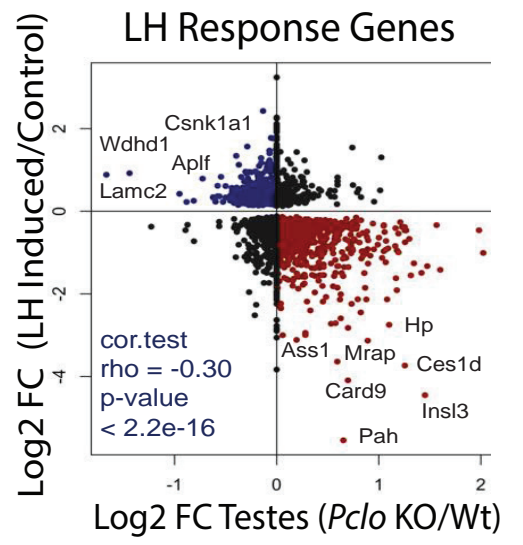

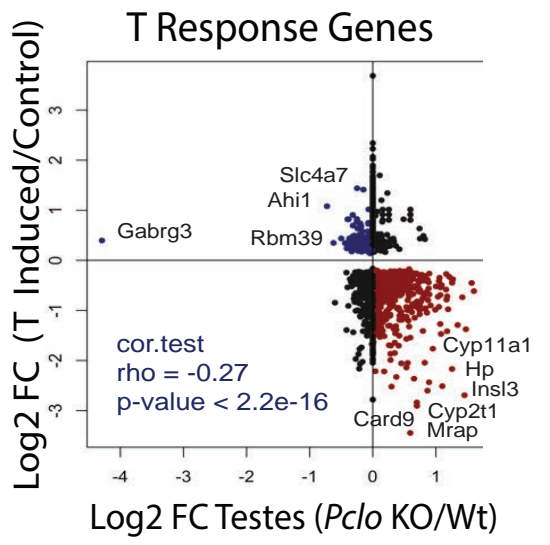


A
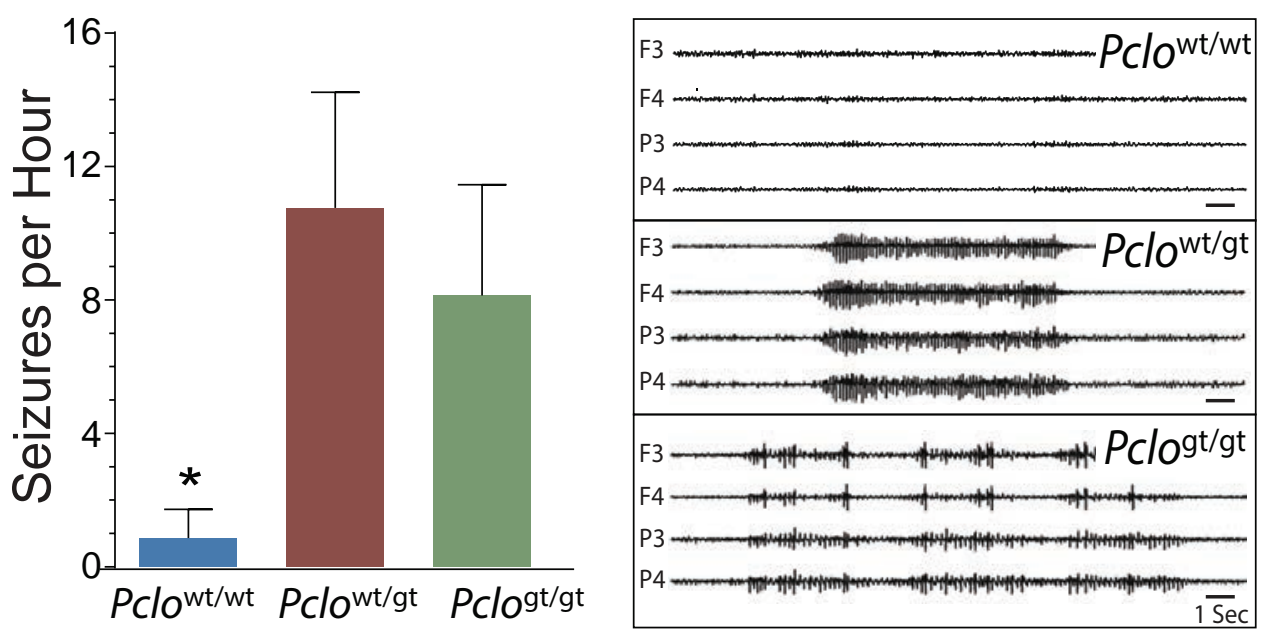

B

Frame

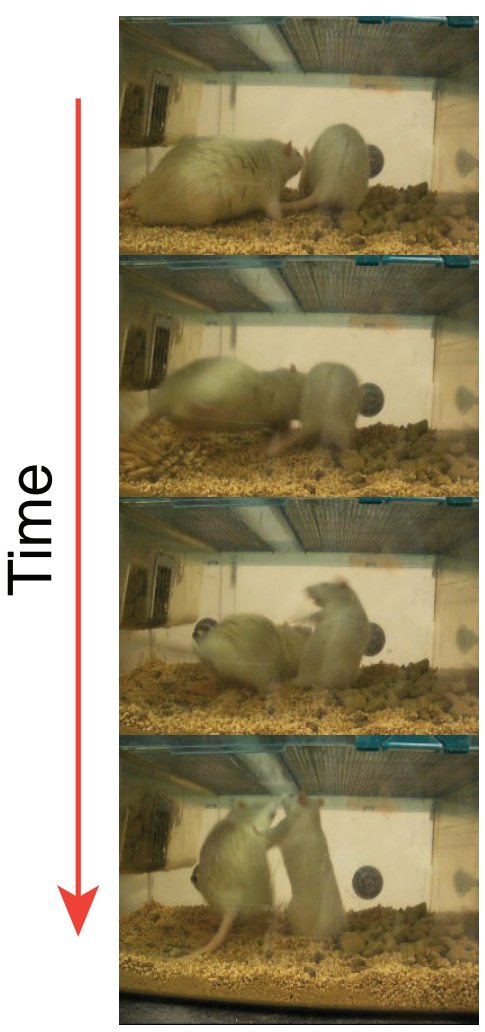

Example 1
Frame

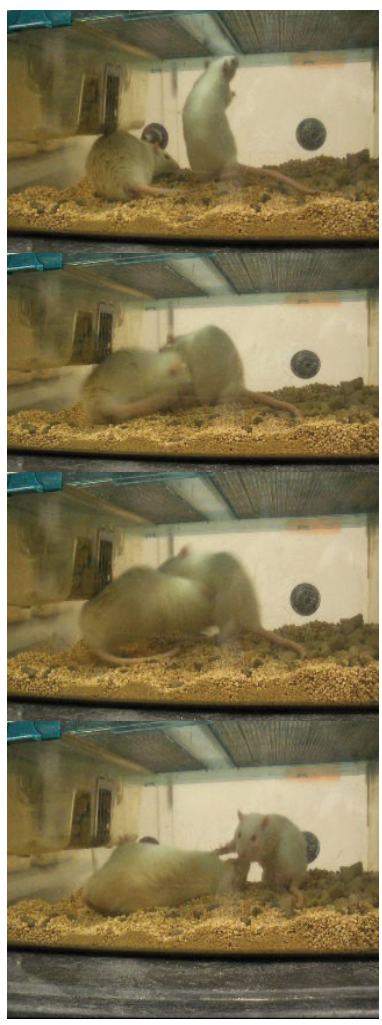

Example 2

Aggressive Behavior 
bioRxiv preprint doi: https://doi org/10.1101/405985; this version posted March 19,2020. The copyright holder for this preprint (which was not certified by peer review) is the author/funder, who has granted bioRxiv a license to display the preprint in perpetuity. It is made available under aCC-BY-NC-ND 4.0 International license.

A

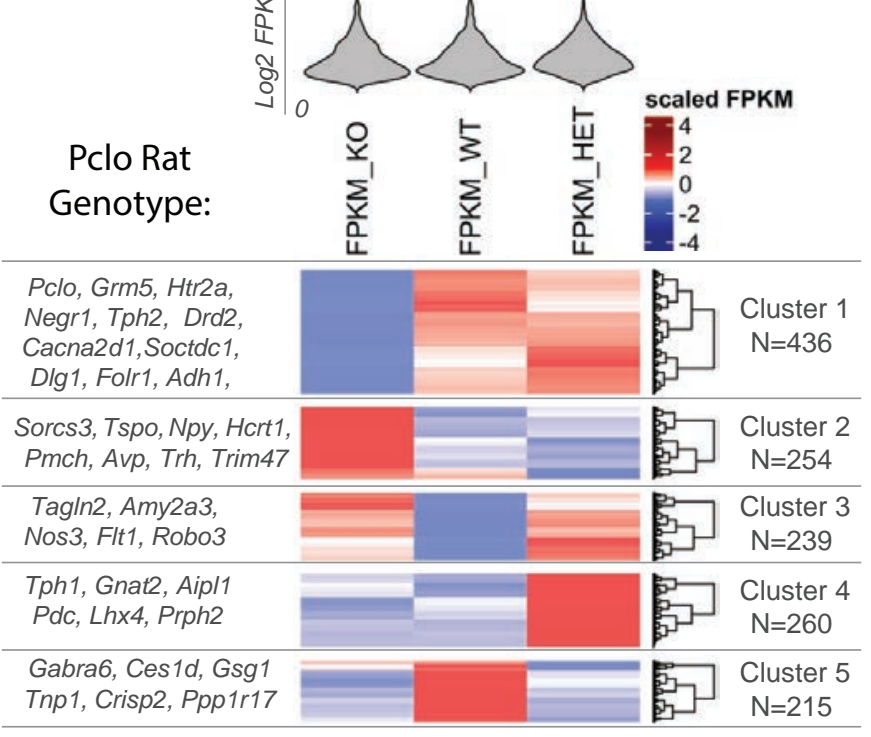

B

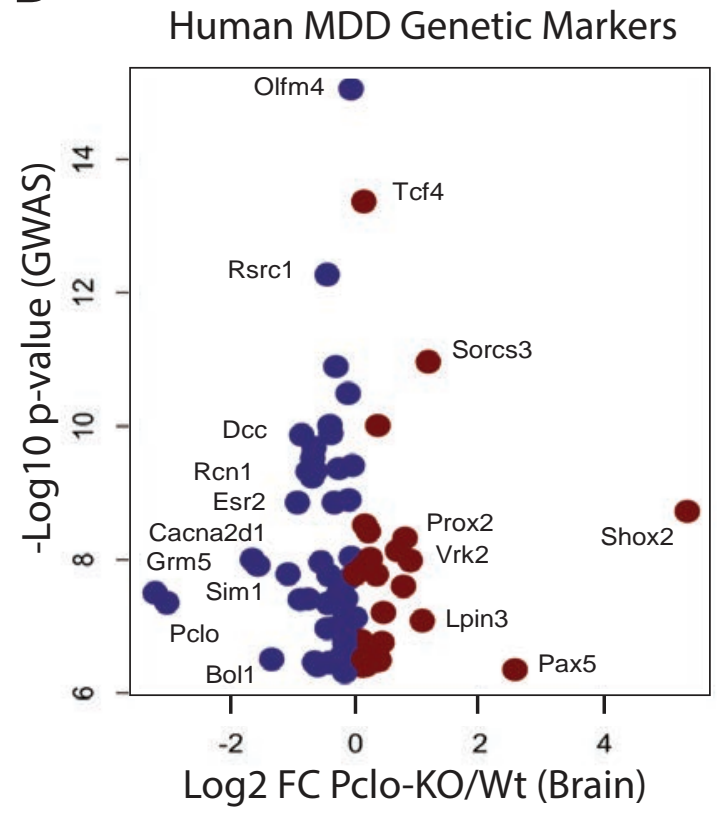

C

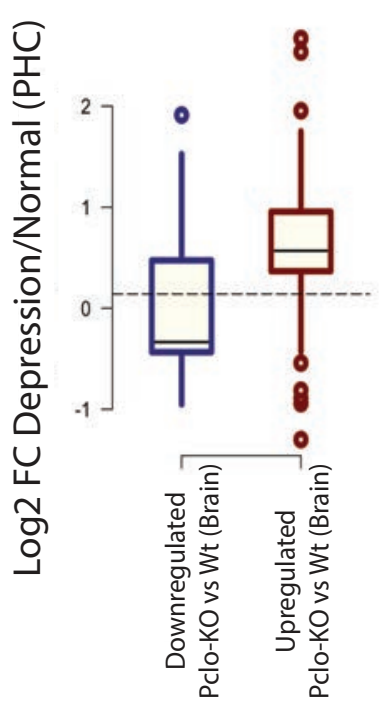

\section{D}

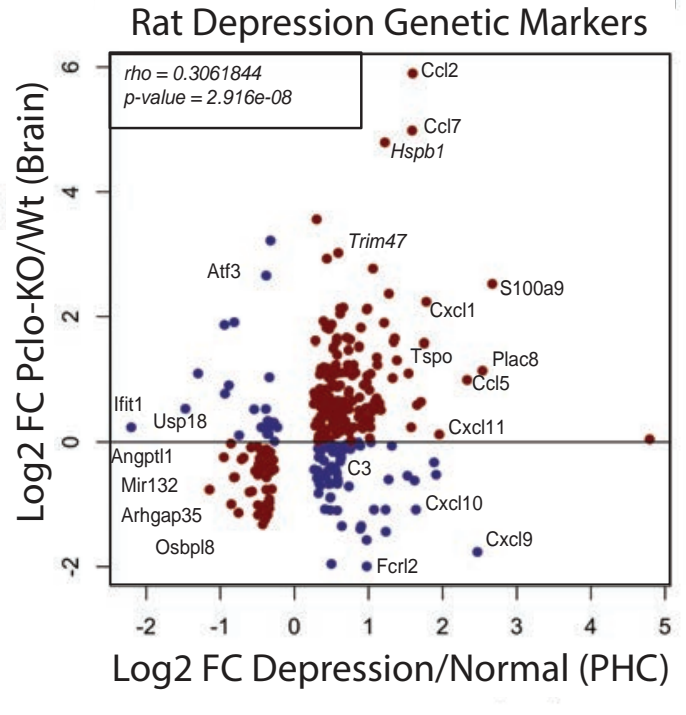

E

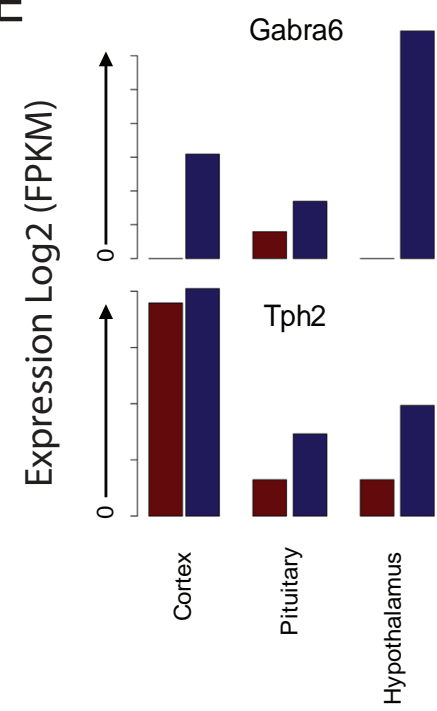

Depression Model Control Rats 


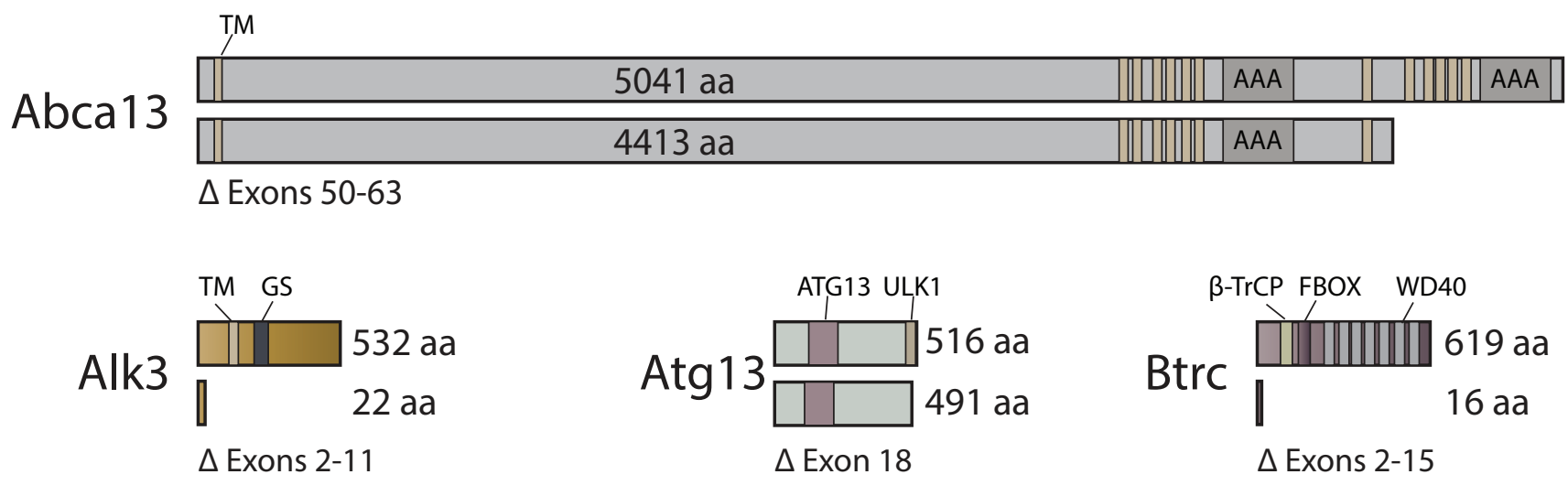

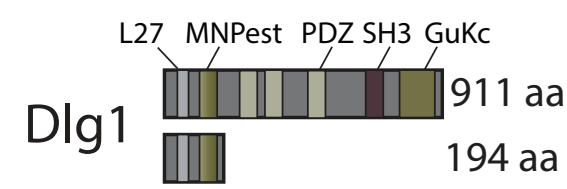

$\Delta$ Exons 7-29

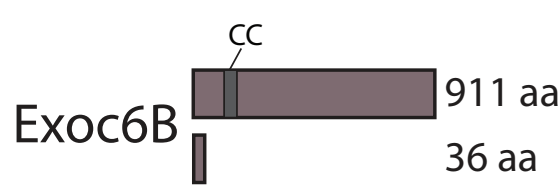

$\Delta$ Exons $2-22$
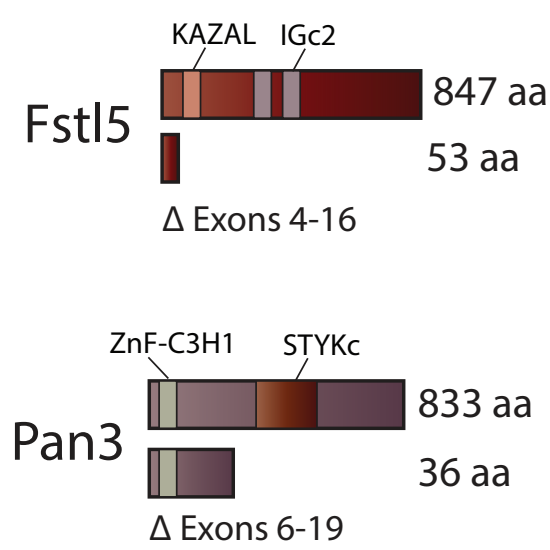

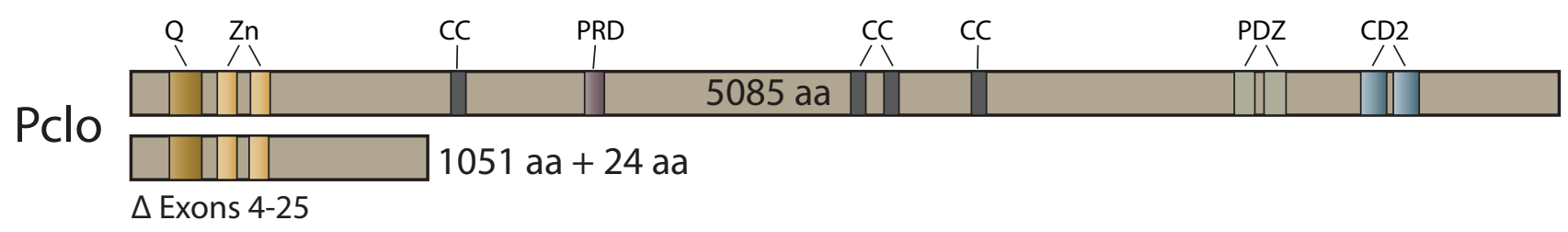

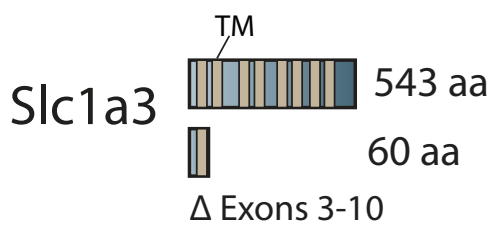

Ube2k $\prod_{\substack{\Delta \text { Exons } 2-7 \\ 21}} 200$ aa
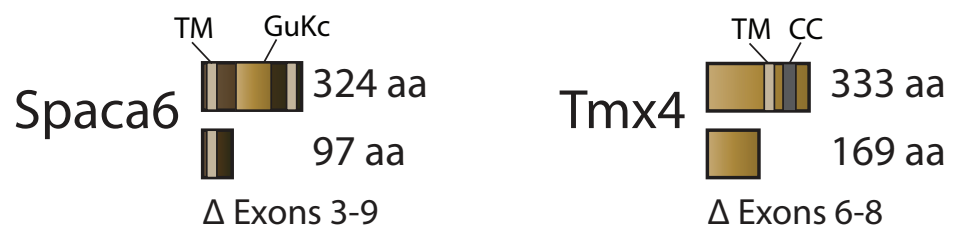

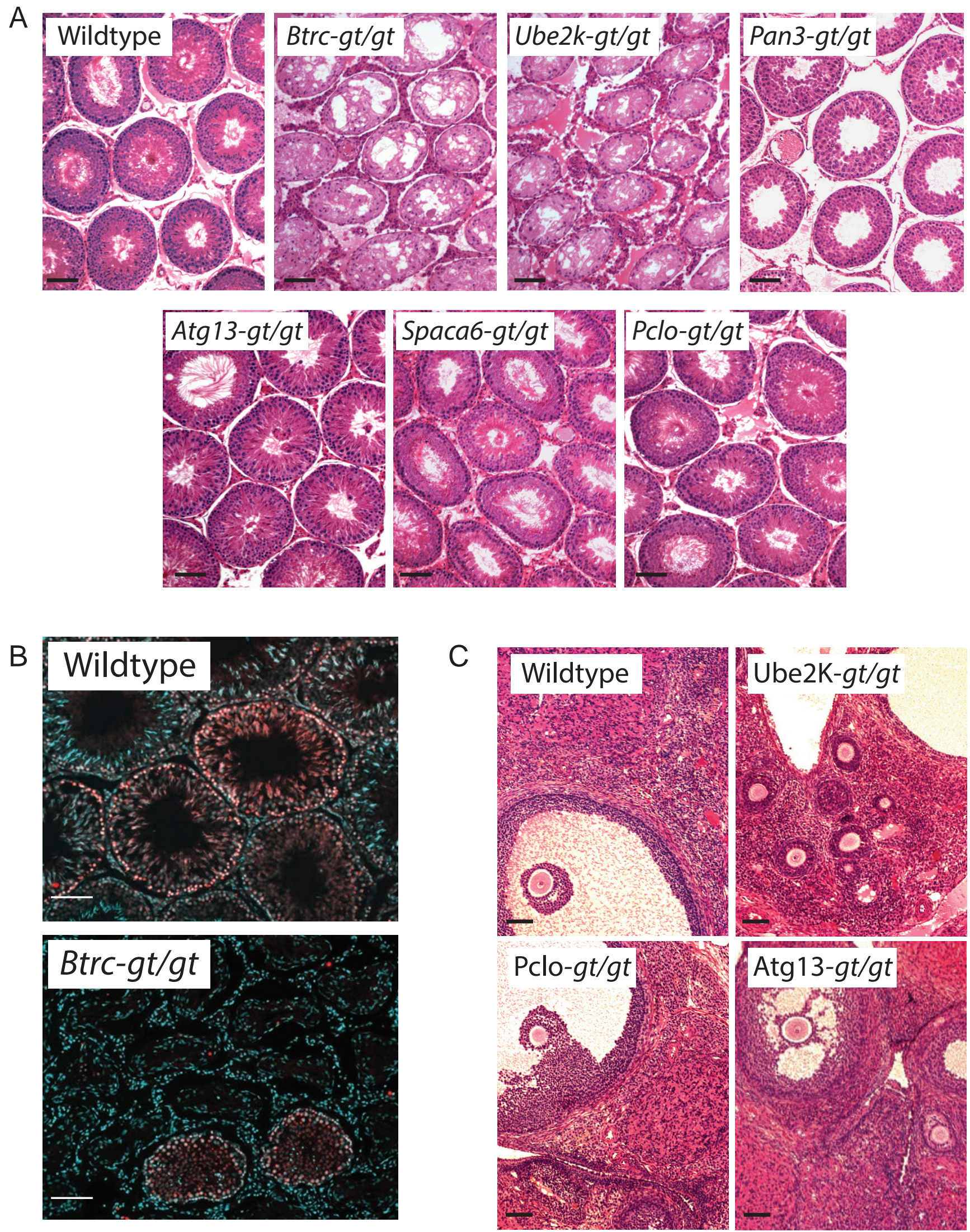

$y-H 2 A X$

Hoechst 33342 
bioRxiv preprint doi: https://doi org/10.1101/405985; this version posted March 19, 2020. The copyright holder for this preprint (which was not certified by peer review) is the author/funder, who has granted bioRxiv a license to display the preprint in perpetuity. It is made available under aCC-BY-NC-ND 4.0 International license.

S3 Fig

A

Panther Pathway Analysis: Pclogt/gt vs Pclowt/wt Rat Brains Total Genes 754 ; Total Pathway Hits $=440$ Genes

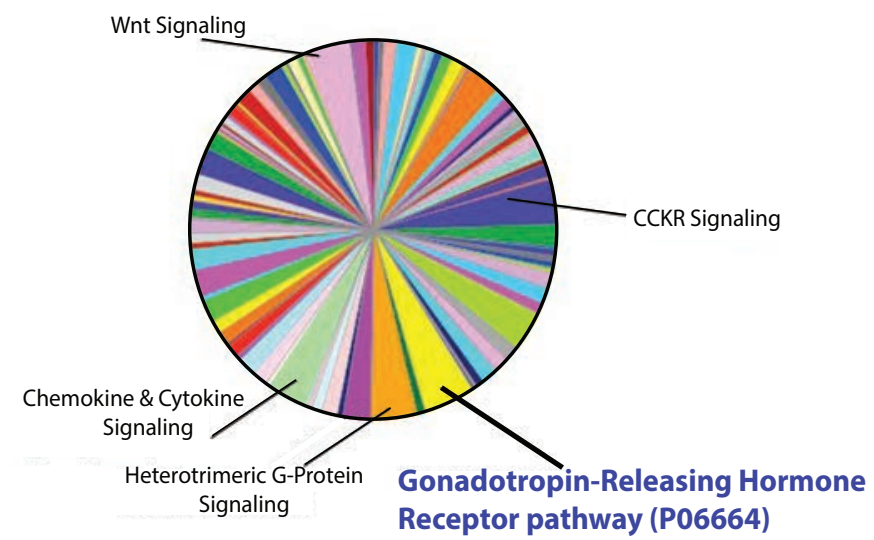

B

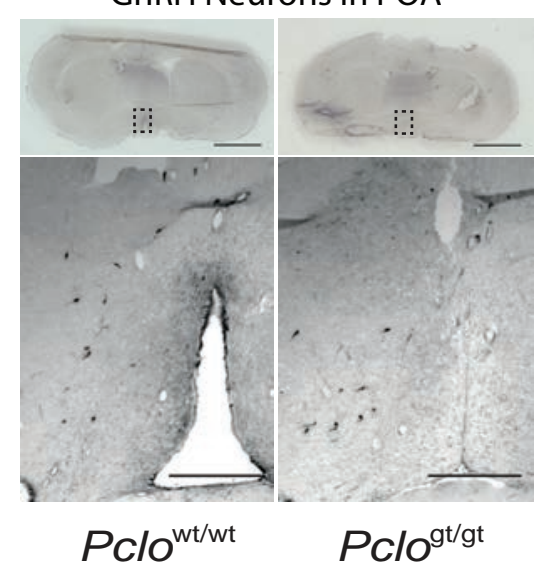

C

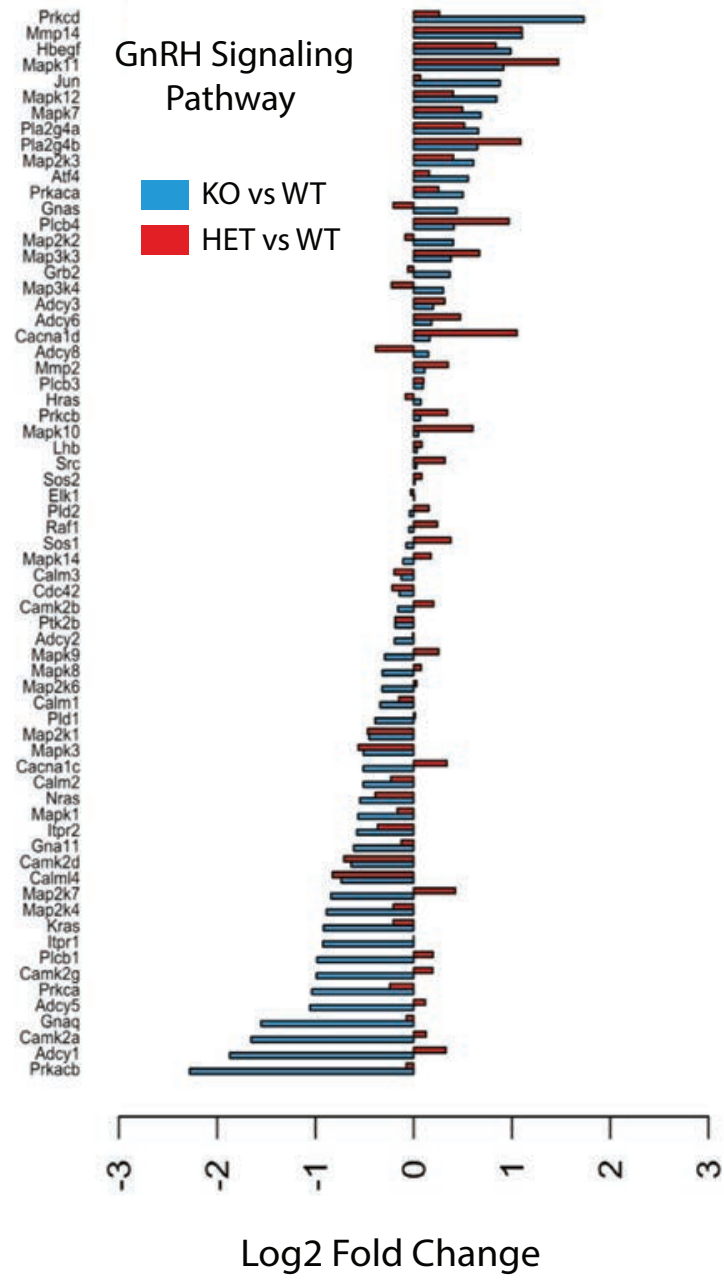

D GnRH Signaling Pathway: Pclogt/gt vs. Pclowt/wt

IDown Regulated $\uparrow$ Up Regulated

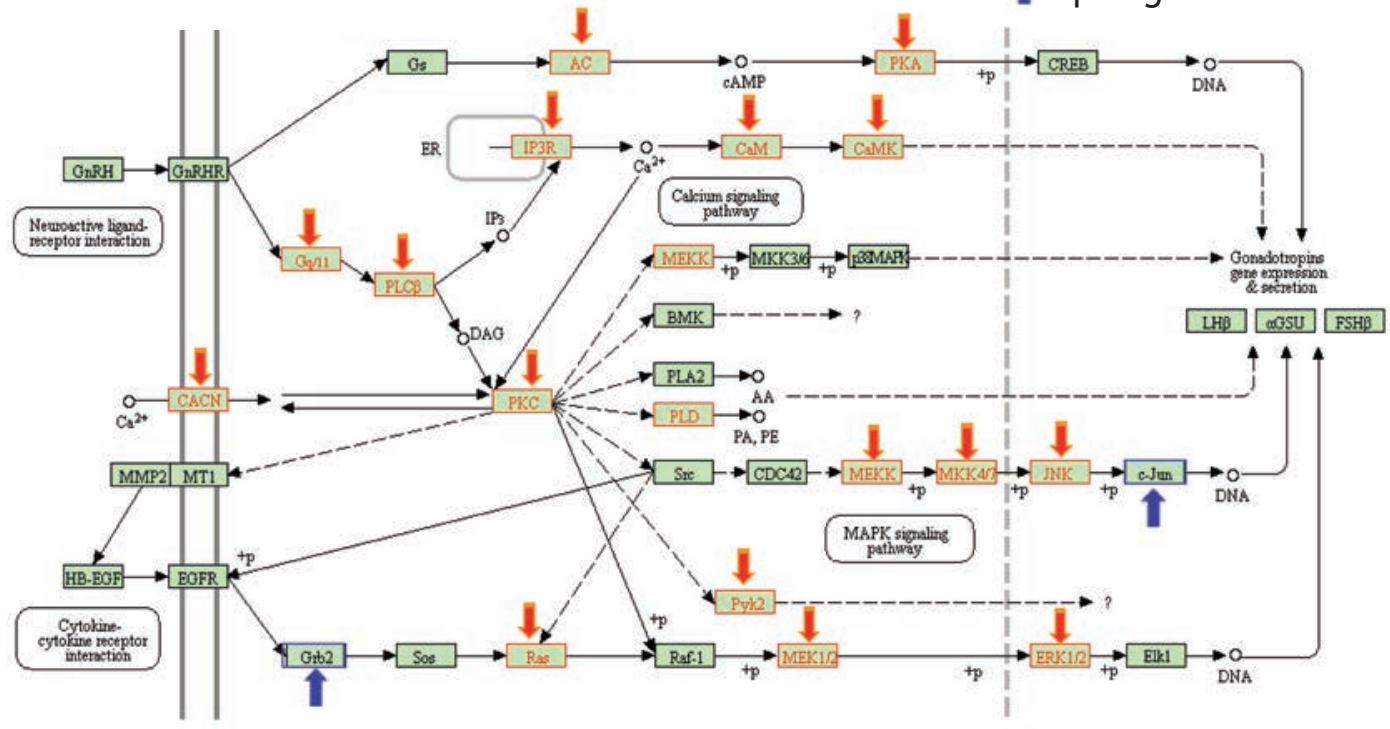


bioRxiv preprint doi: https://doi.org/10.1101/405985; this version posted March 19, 2020. The copyright holder for this preprint (which was not certified by peer review) is the author/funder, who has granted bioRxiv a license to display the preprint in perpetuity. It is made available under aCC-BY-NC-ND 4.0 International license.

A

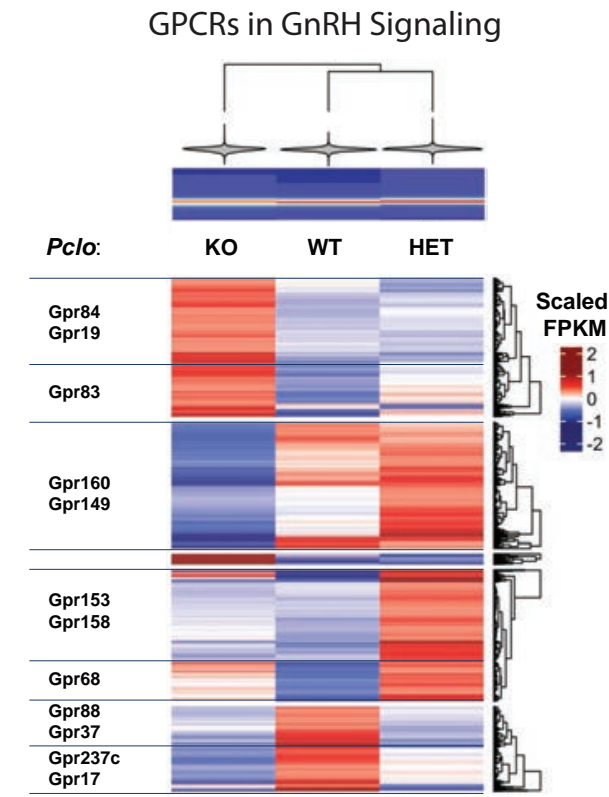

B

\section{Calcium Signaling}
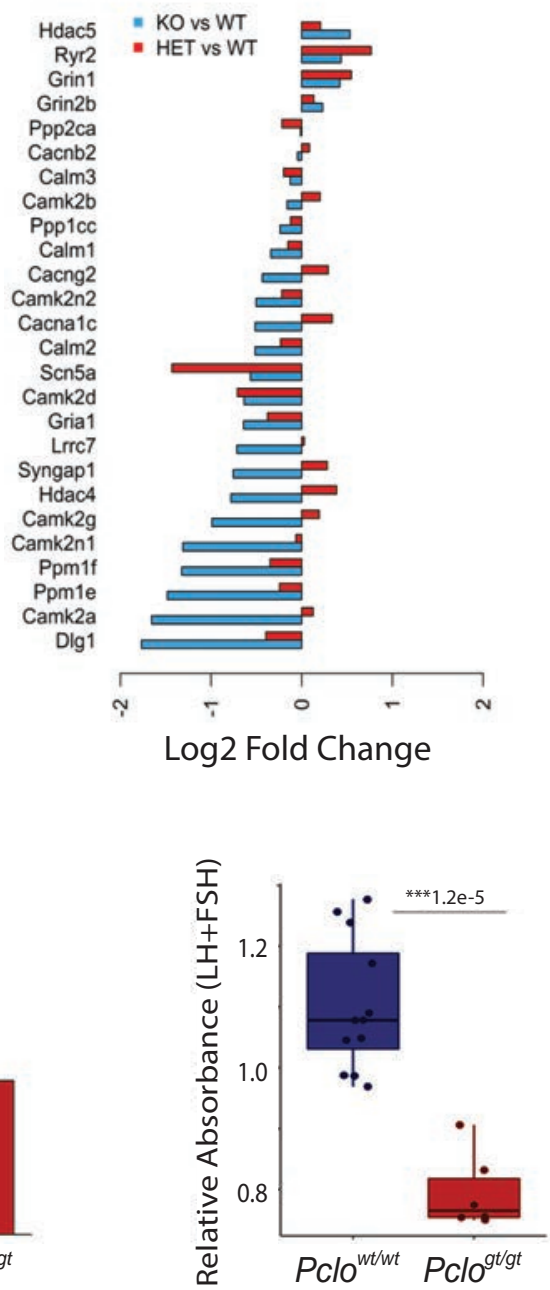

D Gonadotropin Regulated Genes

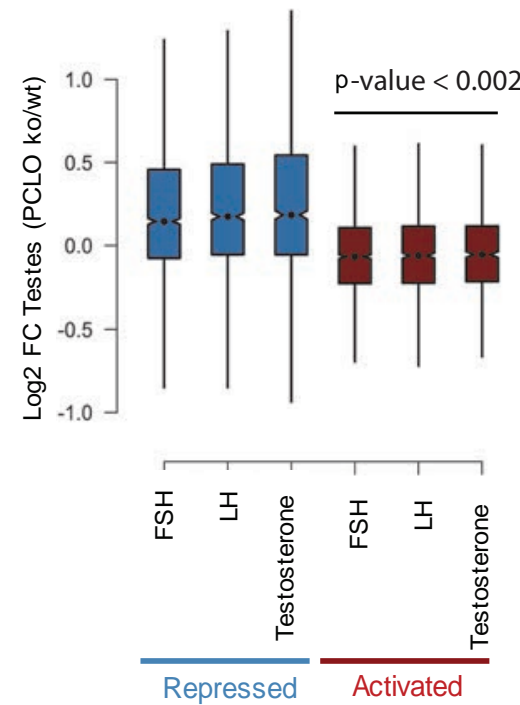

